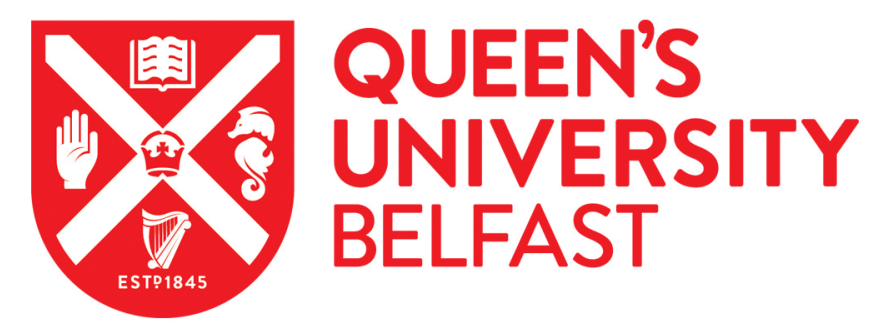

\title{
High-Efficiency Harmonic-Peaking Class-EF Power Amplifiers with Enhanced Maximum Operating Frequency
}

Thian, M., Barakat, A., \& Fusco, V. (2015). High-Efficiency Harmonic-Peaking Class-EF Power Amplifiers with Enhanced Maximum Operating Frequency. IEEE Transactions on Microwave Theory and Techniques, 63(2), 659-671. https://doi.org/10.1109/TMTT.2014.2386327

Published in:

IEEE Transactions on Microwave Theory and Techniques

Document Version:

Peer reviewed version

Queen's University Belfast - Research Portal:

Link to publication record in Queen's University Belfast Research Portal

\begin{abstract}
Publisher rights
(C) 2015 IEEE

Personal use of this material is permitted. Permission from IEEE must be

obtained for all other uses, in any current or future media, including

reprinting/republishing this material for advertising or promotional purposes, creating new collective works, for resale or redistribution to

servers or lists, or reuse of any copyrighted component of this work in other works.

\section{General rights}

Copyright for the publications made accessible via the Queen's University Belfast Research Portal is retained by the author(s) and / or other copyright owners and it is a condition of accessing these publications that users recognise and abide by the legal requirements associated with these rights.
\end{abstract}

\section{Take down policy}

The Research Portal is Queen's institutional repository that provides access to Queen's research output. Every effort has been made to ensure that content in the Research Portal does not infringe any person's rights, or applicable UK laws. If you discover content in the Research Portal that you believe breaches copyright or violates any law, please contact openaccess@qub.ac.uk. 


\title{
High-Efficiency Harmonic-Peaking Class-EF Power Amplifiers with Enhanced Maximum Operating Frequency
}

\author{
Mury Thian, Ayman Barakat and Vincent Fusco, Fellow, IEEE
}

\begin{abstract}
The recently introduced Class-EF power amplifier (PA) has a peak switch voltage lower than that of Class-E PA. However, the value of the transistor output capacitance at high frequencies is typically larger than the required Class-EF optimum shunt capacitance. Consequently, soft-switching operation that minimizes power dissipation during OFF-to-ON transition cannot be achieved at high frequencies. Two new Class-EF PA variants with transmission-line load networks, namely, third-harmonic-peaking (THP) and fifth-harmonicpeaking (FHP) Class-EF PAs are proposed in this paper. These permit operation at higher frequencies at no expense to other PA figures of merit. Analytical expressions are derived in order to obtain circuit component values which satisfy the required ClassEF impedances at fundamental frequency, all even harmonics, and the first few odd harmonics as well as simultaneously providing impedance matching to a $50 \Omega$ load. Furthermore, a novel open-circuit and shorted stub arrangement which has substantial practical benefits is proposed to replace the normal quarter-wave line connected at the transistor's drain. Using GaN HEMTs, two PA prototypes were built. Measured peak drain efficiency of $91 \%$ and output power of $39.5 \mathrm{dBm}$ were obtained at 2.22 GHz for the THP Class-EF PA. The FHP Class-EF PA delivered output power of $41.9 \mathrm{dBm}$ with $85 \%$ drain efficiency at 1.52 GHz.
\end{abstract}

Index Terms-Class-E, Class-EF, Class-F, fifth-harmonicpeaking, GaN, HEMT, power amplifiers, third-harmonicpeaking, transmission lines.

\section{INTRODUCTION}

$\mathrm{T}$ HE Class-E power amplifier (PA) [1]-[5] theoretically offers $100 \%$ DC-to-RF efficiency since its switch voltage and current waveforms are tailored such that they do not overlap each other. It adopts zero voltage switching (ZVS) and zero voltage derivative switching (ZVDS) conditions so as to enable soft-switching operation which minimizes power dissipation during OFF-to-ON transition. However, the peak switch voltage of Class-E PA is considerably high. The Inverse Class-E PA [6]-[8] and Class-F PA [9]-[13] offer

Manuscript received September 1, 2014; revised November 12, 2014 and December 5, 2014; accepted December 21, 2014. This work was supported by the Northern Ireland Department for Employment and Learning (DEL) under Strengthening All Island Mobile Wireless Futures programme and by the FP7 Marie Curie EID programme under ARTISAN project.

The authors are with the Queen's University of Belfast, ECIT Institute, Queen's Road, Queen's Island, Belfast, BT3 9DT, United Kingdom (e-mail: m.thian@qub.ac.uk). substantially lower peak switch voltage than the Class-E counterpart but cannot facilitate soft-switching operation since their idealized circuit topologies do not incorporate a shunt capacitance $(C)$ that is connected in parallel with the switch. In practice, this means that the transistor output capacitance ( $\left.C_{\text {OUT }}\right)$ cannot be effectively absorbed. The output capacitance of an actual transistor typically has nonlinear characteristic since it depends on instantaneous drain-source voltage values. The analysis in [14] presented a design methodology for Class-E PA wherein the nonlinear output capacitance can be adequately approximated with an equivalent linear capacitance.

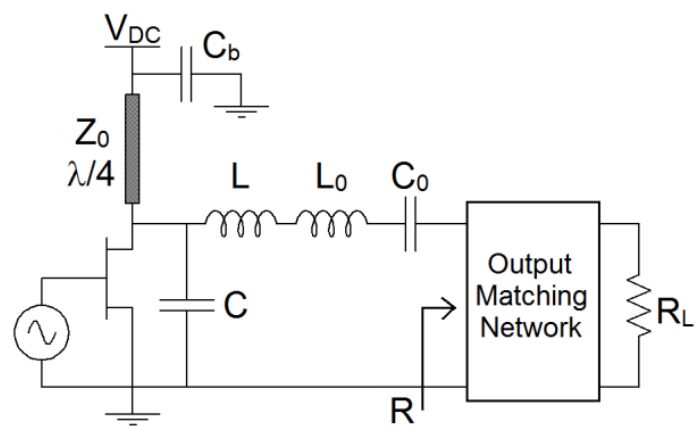

(a)

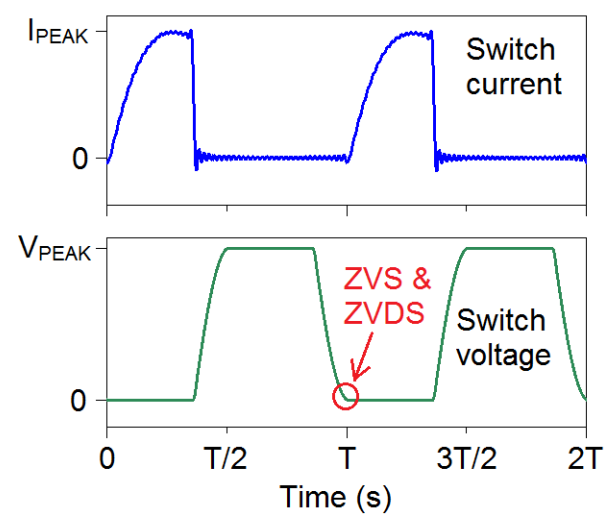

(b)

Fig. 1. Class-EF PA with lumped-element load-network: (a) Basic circuit (b) Idealized steady-state switch voltage and current waveforms.

The Class-EF PA and its variants reported in [15]-[20] offer a low peak switch voltage of only $2 V_{\mathrm{DC}}$ as in the Class $\mathrm{F}$ as well as soft-switching operation as in the Class E, Fig. 1. 
Further, since the switch voltage has maximally flat peak, Fig. 1(b), the Class-EF PA is relatively immune to the detrimental effects that the nonlinear output capacitance has on its performance.

A major challenge in Class-EF PA design is that for a given output power and DC supply voltage $\left(V_{\mathrm{DC}}\right)$, the maximum operating frequency $\left(f_{\mathrm{MAX}}\right)$ is constrained by the transistor output capacitance $\left(C_{\text {OUT }}\right)$, i.e., at high frequencies the value of $C_{\text {OUT }}$ is typically larger than the value of $C$, Fig. 1(a), that results from the Class-EF synthesis. An external shunt inductance $\left(L_{\mathrm{P}}\right)$ can be used to tune out the excess capacitance $C_{\mathrm{X}}\left(=C_{\mathrm{OUT}}-C\right)$ at the fundamental frequency. However, the net reactance of this parallel circuit $L_{\mathrm{P}}-C_{\mathrm{X}}$ at higher harmonics $\left(2 f_{0}, 3 f_{0}\right.$, etc.) would be capacitive. As a consequence, the open-circuit requirement at odd harmonics for optimum Class$\mathrm{EF}$ operation would be violated. The theoretical analysis in [20] demonstrates that the $f_{\text {MAX }}$ of the Class-EF PA can be increased by reducing the duty ratio, by switching the transistor ON for a shorter period. However, this strategy results in low power-output capability and low load resistance. The fact that large devices with high-power-handling capability are always accompanied with high $C_{\text {OUT }}$ would appear to render the Class-EF PA topology unsuitable for high power applications.

In order to address the aforementioned issues, we introduce two new variants of the Class-EF PA, namely third-harmonicpeaking (THP) and fifth-harmonic-peaking (FHP) Class-EF PAs. Synthesized in the frequency domain, these PAs employ a simple transmission-line load network and allow operation at higher $f_{\text {MAX }}$. While the THP Class-EF PA satisfies the opencircuit termination requirement at $3 f_{0}$ alone, the FHP Class-EF PA [21] satisfies the requirement simultaneously at $3 f_{0}$ and $5 f_{0}$. On the other hand, the requirement for short-circuit termination at all even harmonics is satisfied through deployment of a quarter-wave ( $\lambda / 4)$ line connected at the drain. Closed-form expressions are analytically derived not only to satisfy the Class-EF load-impedance requirements at the fundamental frequency, all even harmonics, and the first few odd harmonics but also to simultaneously provide an impedance matching to $50-\Omega$ load thus obviating the need for additional output matching circuitry. Since the open-circuit conditions at $3 f_{0}$ and $5 f_{0}$ are satisfied and all even harmonic components are shorted by the $\lambda / 4$ line, high purity output spectrum can be obtained from the FHP Class-EF PA load network. This relaxes the design specifications for additional filtering typically required at the PA output for compliance with standardized out-of-band emission regulations. Further, when compared to the Class- $\mathrm{E}_{3} \mathrm{~F}$ and Class $\mathrm{E}_{3} \mathrm{~F}_{2}$ PAs in [20], the new PAs generate a less distorted output signal. In addition, these new PAs employ novel $\lambda / 8$ open-circuit and shorted stubs which replace the classical $\lambda / 4$ transmission line (TL). This arrangement offers better open- and short-circuit terminations and has the capability to independently control open- and short-circuit terminations at the transistor's drain, which in turn improve the PA's efficiency.

This paper is organized as follows: basic operation of the Class-EF PA with lumped-element load network along with some design trade-offs awareness is briefly reviewed in Section II. Sections III and IV present the theoretical analysis of the THP and FHP Class-EF PAs, respectively. Circuit design examples and simulations using ideal components are treated in Section V. Finally in Section VI, implementation of the PAs using GaN HEMTs and measurement results are discussed.

\section{REVIEW OF CLASS-EF POWER AMPLIFIER}

The circuit schematic for the Class-EF PA is depicted in Fig. 1(a). The transistor must be driven sufficiently hard such that it operates like a switch rather than a current source. The optimal load impedances at fundamental frequency and higher harmonics seen by the transistor, $Z_{\mathrm{OPT}}$, are given in (1). The load network will present $R$ in series with $L$ at $f_{0}$, a short circuit at all even harmonics, and an open circuit at all odd harmonics. For prescribed output power $\left(P_{\mathrm{O}}\right)$, DC supply voltage $\left(V_{\mathrm{DC}}\right)$, and operating frequency $\left(f_{0}\right)$, the optimal load resistance $R$ and series inductance $L$ can be calculated using (2)-(3). The shunt capacitance $C$ may entirely furnish the device output capacitance $C_{\text {OUT }}$ and its value is given in (4). Note that in (2)-(4) the parameter named dead time $\tau_{\mathrm{D}}$ (in rad) is related to duty ratio $D$ by $D=0.5-\tau_{\mathrm{D}} /(2 \pi)$. For example, $\tau_{\mathrm{D}}=\pi / 2 \mathrm{rad}$ corresponds to $D=0.25$ meaning that the transistor will be switched oN for a period of $25 \%$ of the full cycle.

A quarter-wave line is employed at the drain of the transistor so as to enforce short-circuit termination at all even harmonics. Steady-state switch voltage and current waveforms of the Class-EF PA are illustrated in Fig. 1(b) and the peak switch voltage is $2 V_{\mathrm{DC}}$. By substituting $C=C_{\text {OUT }}$ into (4), the expression for $f_{\text {MAX }}$ can be obtained, (5). $P_{\text {MAX }}(6 a)$ is defined as a ratio between output power and the product of peak switch voltage and peak switch current (6b).

$$
Z_{\text {OPT }}=\left\{\begin{array}{cl}
R+j \omega_{0} L & \text { at } f_{0} \\
0 & \text { at } 2 n f_{0}, n=1,2,3, \ldots \\
\infty & \text { at }(2 n+1) f_{0}, n=1,2,3, \ldots
\end{array}\right.
$$

$$
\begin{aligned}
& R=\frac{2\left(1+\cos \tau_{D}\right)^{2}}{\pi^{2}} \frac{V_{D C}^{2}}{P_{O}} \\
& L=\frac{\tau_{D}-0.5 \sin \left(2 \tau_{D}\right)}{\sin ^{2} \tau_{D}} \frac{R}{\omega_{0}} \\
& C=\frac{\pi}{2}\left(\frac{\sin \tau_{D}}{1+\cos \tau_{D}}\right)^{2} \frac{P_{O}}{\omega_{0} V_{D C}^{2}} \\
& f_{M A X}=\frac{1}{4\left(\frac{\sin \tau_{D}}{1+\cos \tau_{D}}\right)^{2} \frac{P_{O}}{C_{O U T} V_{D C}^{2}}} \quad ; \quad ; \quad \begin{array}{ll}
\left(1+\cos \tau_{D}\right) /(4 \pi) & ; \pi / 2<\tau_{D}<\pi \\
\left(1+\cos \tau_{D}\right) /\left(4 \pi \sin \tau_{D}\right)
\end{array}
\end{aligned}
$$




$$
I_{M A X}= \begin{cases}2 I_{R} & ; \tau_{D} \leq \pi / 2 \\ 2 I_{R} \sin \tau_{D} & ; \pi / 2<\tau_{D}<\pi\end{cases}
$$

where

$$
I_{R}=\frac{\pi}{1+\cos \tau_{D}} I_{D C}
$$

\section{THIRD-HARMONIC-PEAKING CLASS-EF PA WITH ENHANCED $f_{\text {MAX }}$}

A new Class-EF PA circuit topology with transmission-line load network is depicted in Fig. 2. In practice, it is impossible to realize a transmission-line load network that could simultaneously satisfy Class-EF impedance requirements at the fundamental frequency as well as at all even and odd harmonics (1) since this would require an infinite number of transmission lines. However, as will be shown shortly, a good approximation to the idealized Class-EF operation can be achieved by satisfying the required impedances at $f_{0}$, all even harmonics, and only the first few odd harmonics. Here, a third-harmonic-peaking (THP) Class-EF PA is proposed wherein the open-circuit requirement is satisfied at $3 f_{0}$ alone. The circuit is also synthesized to simultaneously provide direct impedance matching into a $50-\Omega$ load.

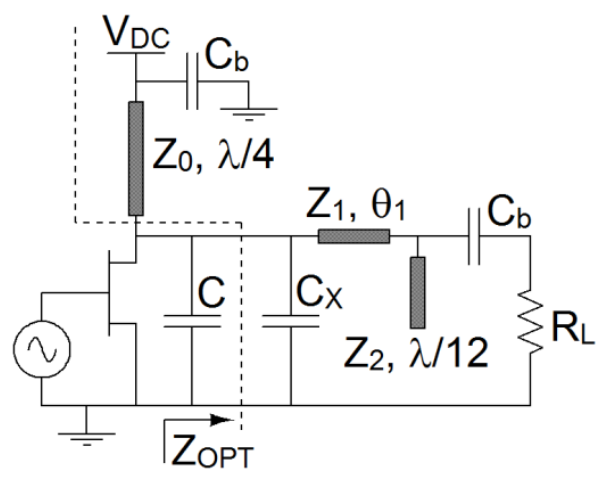

(a)

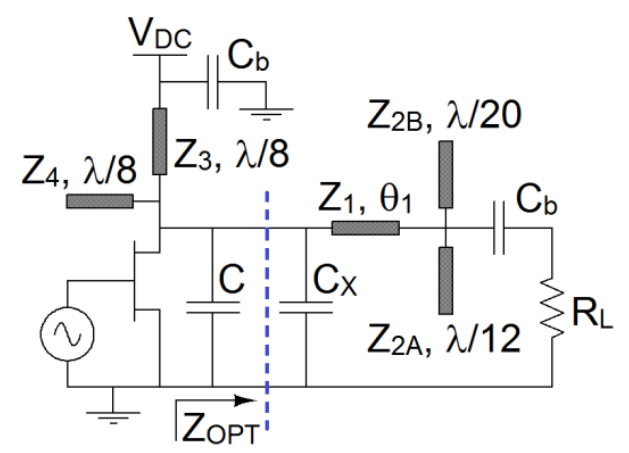

(b)

Fig. 2. Third-harmonic-peaking Class-EF PA with enhanced $f_{\text {MAX }}$ employing: (a) $\lambda / 4$ line, (b) $\lambda / 8$ open and shorted stubs as well as an additional fifthharmonic trap TL $\left(Z_{2 \mathrm{~B}}, \lambda / 20\right)$.

Enhanced $f_{\text {MAX }}$ is achieved by adding extra capacitance $C_{\mathrm{X}}$ to the original Class-EF circuit in Fig. 1(a) and, as a result, the device output capacitance $C_{\mathrm{OUT}}$ now increases to $C+C_{\mathrm{X}}$. This translates into higher $f_{\mathrm{MAX}}$ expressed in (7) where $C_{\mathrm{X}}$ is defined as $k C(k>0)$.

$$
f_{M A X}=\frac{1}{4}\left(\frac{\sin \tau_{D}}{1+\cos \tau_{D}}\right)^{2}(1+k) \frac{P_{O}}{C_{O U T} V_{D C}^{2}}
$$

\section{A. Basic Circuit}

The electrical length of the open-circuit stub $\mathrm{TL}_{2}$ in Fig. 2(a) is $90^{\circ}$ at $3 f_{0}$ and therefore it provides a short-circuit termination to the series line $\mathrm{TL}_{1}$. This shorted series line behaves like an inductance $\left(L_{1}\right)$. This inductance must be resonated with $C_{\mathrm{X}}$ in order to provide the required Class-EF open circuit at $3 f_{0}$, hence (8).

$3 \omega_{0} C_{X} \tan \left(3 \theta_{1}\right)=Y_{1}$

At the fundamental frequency, the $50 \Omega$ load resistance $\left(R_{\mathrm{L}}\right)$ is transformed by $\mathrm{TL}_{1}$ and $\mathrm{TL}_{2}$ into an admittance of $1 / Z_{\mathrm{OPT}}$ $j \omega_{0} C_{\mathrm{X}}$ where $Z_{\mathrm{OPT}}$ is given in (1). This results in:

$G_{O P T}=\frac{G_{L} Y_{1}^{2} \sec ^{2} \theta_{1}}{\left(Y_{1}-B_{L} \tan \theta_{1}\right)^{2}+G_{L}^{2} \tan ^{2} \theta_{1}}$
$\frac{B_{O P T}-\omega_{0} C_{X}}{Y_{1}}=\frac{\left(Y_{1} \tan \theta_{1}+B_{L}\right)\left(Y_{1}-B_{L} \tan \theta_{1}\right)-G_{L}^{2} \tan \theta_{1}}{\left(Y_{1}-B_{L} \tan \theta_{1}\right)^{2}+G_{L}^{2} \tan ^{2} \theta_{1}}$

where:

$$
\begin{aligned}
& G_{O P T}=\frac{R}{R^{2}+\left(\omega_{0} L\right)^{2}} \\
& B_{O P T}=\frac{-\omega_{0} L}{R^{2}+\left(\omega_{0} L\right)^{2}} \\
& G_{L}=1 / R_{L}=1 / 50 \\
& B_{L}=Y_{2} \tan 30^{\circ}=Y_{2} / \sqrt{3}
\end{aligned}
$$

By solving (8)-(10) simultaneously, the values of $Z_{1}$ $\left(=1 / Y_{1}\right), \theta_{1}$, and $Z_{2}\left(=1 / Y_{2}\right)$ can be obtained. The characteristic impedance of the quarter-wave line $Z_{0}$ must be selected sufficiently high so as to isolate the supply voltage from the $\mathrm{RF}$ signal. Note that $C_{\mathrm{b}}$ is a DC-blocking capacitance.

\section{B. Modified Load Network}

To facilitate for fifth-harmonic suppression, the single open-circuit stub $\left(Z_{2}, 30^{\circ}\right)$ in Fig. 2(a) is modified into two open-circuit stubs with electrical lengths of $30^{\circ}$ and $18^{\circ}$, Fig. 2(b). Their respective characteristic admittances $Y_{2 \mathrm{~A}}$ and $Y_{2 \mathrm{~B}}$ are:

$Y_{2 A}=Y_{2 B}=\frac{Y_{2} \tan 30^{\circ}}{\tan 30^{\circ}+\tan 18^{\circ}} \approx 0.64 Y_{2}$

where $Y_{2 \mathrm{~A}}=1 / Z_{2 \mathrm{~A}}$ and $Y_{2 \mathrm{~B}}=1 / Z_{2 \mathrm{~B}}$. 
Furthermore, novel $\lambda / 8$ open-circuit and shorted stubs are now used to replace the traditional $\lambda / 4$ line. The $\lambda / 8$ open stub will short circuit the drain of the transistor at $(4 m-2)^{\text {th }}$ harmonics whereas the $\lambda / 8$ shorted stub will short circuit the drain of the transistor at $4 m^{\text {th }}$ harmonics where $m=1,2,3$, etc. Together they will facilitate a short-circuit termination at all even harmonics. At the fundamental frequency, the $\lambda / 8$ shorted stub behaves like an inductance $L_{3}$ (16) while the $\lambda / 8$ open stub behaves like a capacitance $C_{4}(17)$. This parallel $L_{3}-C_{4}$ circuit is designed to resonate at $f_{0}(18)$.

$$
\begin{aligned}
& j \omega_{0} L_{3}=j Z_{3} \tan 45^{\circ}=j Z_{3} \\
& j \omega_{0} C_{4}=j Y_{4} \tan 45^{\circ}=j Y_{4} \\
& \omega_{0}^{2} L_{3} C_{4}=1
\end{aligned}
$$

Substitution of (16) and (17) into (18) results in:

$Z_{3}=Z_{4}$

By setting $Z_{3}$ equal to $Z_{4}$, the proposed stub arrangement provides an open circuit not only at $f_{0}$ but also at all odd harmonics.

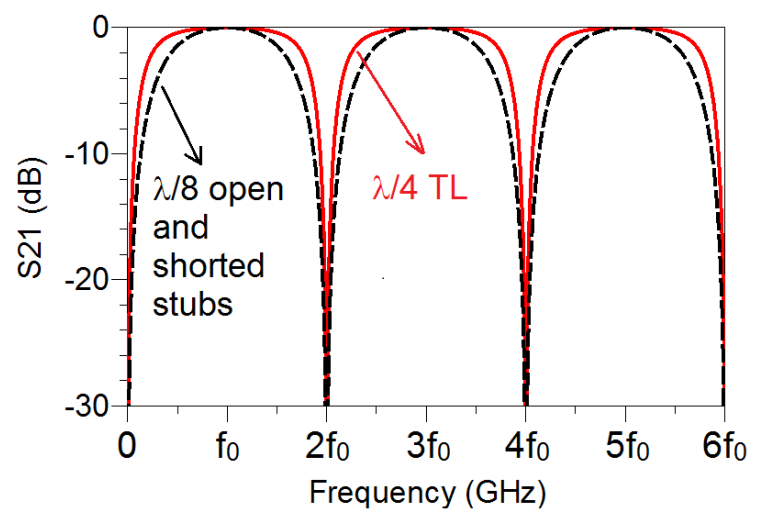

Fig. 3. Characteristics of $\lambda / 8$ open and shorted stubs vs $\lambda / 4$ TL.

The bandwidth characteristic of the $\lambda / 8$ open-circuit and shorted stubs at $f_{0}$ and higher harmonics is compared with the $\lambda / 4 \mathrm{TL}$ in Fig. 3. It can be observed that the rejection band $(|\mathrm{S} 21| \leq-10 \mathrm{~dB})$ of the proposed arrangement is twice as large as that of the $\lambda / 4 \mathrm{TL}$. For illustration, suppose $f_{0}=2.5 \mathrm{GHz}$. The new $\lambda / 8$ stubs will provide useful attenuation $\geq 10 \mathrm{~dB}$ from $4.68 \mathrm{GHz}$ to $5.32 \mathrm{GHz}$ (rejection bandwidth $=640$ $\mathrm{MHz}$ ). At one half these frequencies i.e., from $2.34 \mathrm{GHz}$ to $2.66 \mathrm{GHz}$ (pass-band bandwidth $=320 \mathrm{MHz}$ ), insertion loss is better than $0.017 \mathrm{~dB}$. Meanwhile, the traditional $\lambda / 4$ line will provide the same level of insertion loss i.e., better than 0.017 $\mathrm{dB}$ from $2.18 \mathrm{GHz}$ to $2.82 \mathrm{GHz}$ (pass-band bandwidth $=640$ $\mathrm{MHz}$ i.e., twice as large as that of the $\lambda / 8$ stubs). However, the rejection levels at $2 \mathrm{x}$ these frequencies i.e., from $4.36 \mathrm{GHz}$ to $5.64 \mathrm{GHz}$ are only $\geq 1.875 \mathrm{~dB}$. Therefore it is misleading to conclude that the pass-band bandwidth of the $\lambda / 4$ line is superior. The correct way to interpret the graph in Fig. 3 is as follows. The $\lambda / 4$ line will provide attenuation $\geq 10 \mathrm{~dB}$ from
4.84 $\mathrm{GHz}$ to $5.16 \mathrm{GHz}$ (rejection bandwidth $=320 \mathrm{MHz}$ i.e., one half that of the $\lambda / 8$ stubs) and this is translated into a passband bandwidth of $160 \mathrm{MHz}$ i.e., from $2.42 \mathrm{GHz}$ to $2.58 \mathrm{GHz}$. In other word, although the insertion loss of the $\lambda / 4$ line is low across $2.18-2.82 \mathrm{GHz}$ frequency range, only a fraction of this bandwidth i.e., from $2.42 \mathrm{GHz}$ to $2.58 \mathrm{GHz}$ is useful since they result in sufficient rejection levels $\geq 10 \mathrm{~dB}$.

In practice, the $\lambda / 4$ line in Fig. 2(a) cannot provide ideal short-circuit termination i.e., $0 \Omega$ at even harmonics as required for Class-EF operation due to parasitic resistance ESR. The effect of ESR on the PA efficiency becomes more pronounced in low-voltage high-power designs when the resistance that the supply voltage presents to the PA $\left(R_{D C}\right)$ is considerably small. Since the physical length of the $\lambda / 8$ open and shorted stubs in Fig. 2(b) is just half of that of the $\lambda / 4$ line, the accompanied ESR will be lower and thus provides better short-circuit termination.

More importantly, the bypass capacitance $C_{\mathrm{b}}$ in Fig. 2 should in theory provide a short circuit at the fundamental frequency as well as at all even and odd harmonics. However, in practice, one capacitor can only be used to provide low impedance (typically around $1 \Omega$ ) at a single frequency. For example, in order to provide a short circuit at $f_{0}$ and higher harmonics up to $6 f_{0}$, six capacitors are needed. In contrast, the PA in Fig. 2(b) only needs four capacitors since the shortcircuit terminations at the drain at $2 f_{0}$ and $6 f_{0}$ are enforced by the $\lambda / 8$ open-circuit stub and therefore no capacitors are required. Another practical advantage is that the $\lambda / 8$ open stub will present lower impedance (close to $0 \Omega$ ) at the drain resulting in better $2^{\text {nd }}$ and $6^{\text {th }}$ harmonics suppression than when $\lambda / 4$ TL and $C_{\mathrm{b}}$ are used.

In addition, when implemented in IC format particularly at millimeter-wave frequencies, the proposed stub arrangement offers more flexibility and superior performance than the traditional $\lambda / 4$ line. In theory a shorted $\lambda / 4$ line can provide short-circuit termination at all even harmonics. In reality, the length of this line can be effectively tuned at just one frequency (typically $2 f_{0}$ ) so as to provide the required lowimpedance termination. In the proposed stub arrangement, the lengths of the $\lambda / 8$ open and shorted stubs can be tuned independently to provide low-impedance termination at $2 f_{0}$ and $4 f_{0}$, respectively.

\section{FIFTH-HARMONIC-PEAKING Class-EF PA WITH ENHANCED $f_{M A X}$}

The circuit schematic for the fifth-harmonic-peaking (FHP) Class-EF PA is depicted in Fig. 4. Here, the Class-EF opencircuit requirement is satisfied for the first two odd harmonics, i.e., $3 f_{0}$ and $5 f_{0}$ rather than just $3 f_{0}$ as in the THP Class-EF PA. As a result it mimics idealized Class-EF operation more closely than the THP Class-EF PA. The FHP Class-EF PA is comprised of $\lambda / 8$ open and shorted stubs which enforce shortcircuit terminations at even harmonics, $C_{\mathrm{X}}$ as a means to enhance $f_{\text {MAX }}$, two series transmission lines $\left(\mathrm{TL}_{1}, \mathrm{TL}_{4}\right)$, three open-circuit stubs $\left(\mathrm{TL}_{2}, \mathrm{TL}_{5}, \mathrm{TL}_{6}\right)$, and a shorted stub $\left(\mathrm{TL}_{3}\right)$. In the analysis below, $Z_{\mathrm{N}}, Y_{\mathrm{N}}\left(=1 / Z_{\mathrm{N}}\right)$ and $\theta_{\mathrm{N}}$ are, respectively, the characteristic impedance, the characteristic admittance, 
and the electrical length of $\mathrm{TL}_{\mathrm{N}}$. Note that $C_{\mathrm{b}}$ is a DC-blocking capacitance and also has a role in preventing the DC signal from being shorted by $\mathrm{TL}_{3}$.

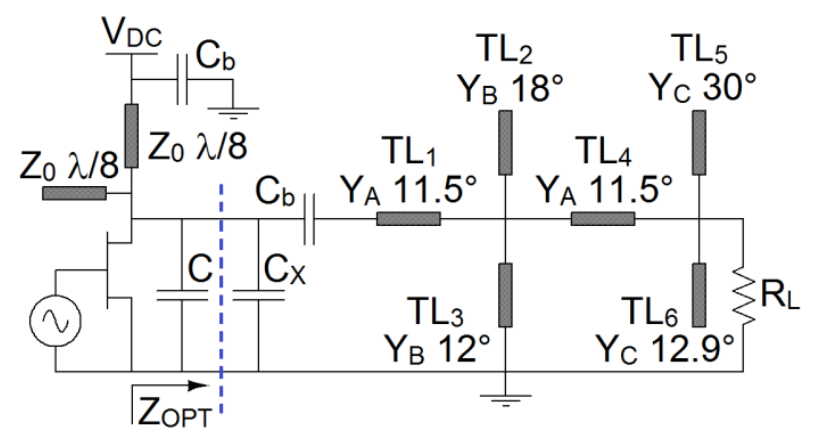

Fig. 4. Fifth-harmonic-peaking Class-EF PA with enhanced $f_{\text {MAX }}$ employing $\lambda / 8$ open and shorted stubs and an additional seventh-harmonic trap $\mathrm{TL}_{6}$

Consider now the following: $\mathrm{TL}_{6}$ in Fig. 4 is absent, $\theta_{2}=18^{\circ}$ and $\theta_{5}=30^{\circ}$.

At $\mathbf{5} \boldsymbol{f}_{\mathbf{0}}$, the right-hand end of $\mathrm{TL}_{1}$ will be shorted by $\mathrm{TL}_{2}$. Provided $\theta_{1}<18^{\circ}$, the shorted $\mathrm{TL}_{1}$ will act like an inductance $L_{1}$ given in (20). This inductance is designed to resonate with $C_{\mathrm{X}}$ at $5 f_{0}$ so as to provide the required Class-EF odd-harmonic open-circuit condition (21).

$$
\begin{aligned}
& j 5 \omega_{0} L_{1}=j Z_{1} \tan \left(5 \theta_{1}\right) \\
& \left(5 \omega_{0}\right)^{2} L_{1} C_{X}=1
\end{aligned}
$$

Substitution of (20) into (21) results in:

$$
Y_{1}=5 \omega_{0} C_{X} \tan \left(5 \theta_{1}\right)
$$

At $\mathbf{3} \boldsymbol{f}_{\mathbf{0}}, \mathrm{TL}_{2}$ and $\mathrm{TL}_{3}$ behave respectively like a capacitance $C_{2}$ and an inductance $L_{3}$, (23)-(24). This parallel circuit is designed to resonate at $3 f_{0}$ and therefore present an open circuit, (25). As a consequence, $\mathrm{TL}_{1}$ and $\mathrm{TL}_{4}$ are now in series connection.

$$
\begin{aligned}
& j 3 \omega_{0} C_{2}=j Y_{2} \tan 54^{\circ} \\
& j 3 \omega_{0} L_{3}=j Z_{3} \tan \left(3 \theta_{3}\right) \\
& \left(3 \omega_{0}\right)^{2} L_{3} C_{2}=1
\end{aligned}
$$

Suppose $Z_{2}=Z_{3}=Z_{\mathrm{B}}$. Substitution of (23) and (24) into (25) yields:

$$
\begin{aligned}
& \tan \left(3 \theta_{3}\right) \tan 54^{\circ}=1 \\
& \theta_{3}=12^{\circ}
\end{aligned}
$$

On the other hand, the right-hand end of $\mathrm{TL}_{4}$ will be shorted by $\mathrm{TL}_{5}$. Provided that $\theta_{1}+\theta_{4}<30^{\circ}, \mathrm{TL}_{1}$ together with the shorted $\mathrm{TL}_{4}$ will behave like an inductance $L_{\mathrm{X}}$ and this inductance is designed to resonate with $C_{\mathrm{X}}$ at $3 f_{0}$, facilitating an open circuit; see (28)-(29) with $Z_{1}=Z_{4}=Z_{\mathrm{A}}$. From (28) and (29), we obtain (30). $j 3 \omega_{0} L_{X}=j Z_{A} \tan \left\{3\left(\theta_{1}+\theta_{4}\right)\right\}$

$\left(3 \omega_{0}\right)^{2} L_{X} C_{X}=1$

$Y_{1}=Y_{4}=Y_{A}=3 \omega_{0} C_{X} \tan \left\{3\left(\theta_{1}+\theta_{4}\right)\right\}$

Substitution of (22) into (30) results in:

$3 \tan \left\{3\left(\theta_{1}+\theta_{4}\right)\right\}=5 \tan \left(5 \theta_{1}\right)$

$\theta_{A}=\theta_{1}=\theta_{4}=11.535^{\circ}$

With $C_{\mathrm{X}}=C_{\mathrm{OUT}}-C$, the characteristic admittance of $\mathrm{TL}_{1}$ and $\mathrm{TL}_{4}, Y_{\mathrm{A}}$, can be computed from either (22) or (30).

At $f_{0}, \mathrm{TL}_{1}-\mathrm{TL}_{5}$ together with $C_{\mathrm{X}}$ will transform the load resistance $R_{\mathrm{L}}$ into $R+j \omega_{0} L$. This results in two equations (33)(34) with two unknown parameters $Y_{\mathrm{B}}\left(=Y_{2}=Y_{3}\right)$ and $Y_{5}$ which can be solved numerically. Note that $R$ and $L$ in (35)(36) are given in (2)-(3).

$G_{O P T}=\frac{G_{I N 2} Y_{A}^{2} \sec ^{2} \theta_{A}}{\left(Y_{A}-B_{I N 2} \tan \theta_{A}\right)^{2}+G_{I N 2}^{2} \tan ^{2} \theta_{A}}$

$\frac{B_{O P T}-\omega_{0} C_{X}}{Y_{A}}=$

$\frac{\left(Y_{A} \tan \theta_{A}+B_{I N 2}\right)\left(Y_{A}-B_{I N 2} \tan \theta_{A}\right)-G_{I N 2}^{2} \tan \theta_{A}}{\left(Y_{A}-B_{I N 2} \tan \theta_{A}\right)^{2}+G_{I N 2}^{2} \tan ^{2} \theta_{A}}$

where:

$G_{O P T}=\frac{R}{R^{2}+\left(\omega_{0} L\right)^{2}}$

$B_{O P T}=\frac{-\omega_{0} L}{R^{2}+\left(\omega_{0} L\right)^{2}}$

$G_{I N 2}=G_{I N 1}$

$B_{I N 2}=B_{I N 1}+Y_{B}\left(\tan 18^{\circ}+\cot 12^{\circ}\right)$

and

$G_{I N 1}=\frac{G_{L} Y_{A}^{2} \sec ^{2} \theta_{A}}{\left(Y_{A}-B_{L} \tan \theta_{A}\right)^{2}+G_{L}^{2} \tan ^{2} \theta_{A}}$

$\frac{B_{I N 1}}{Y_{A}}=\frac{\left(Y_{A} \tan \theta_{A}+B_{L}\right)\left(Y_{A}-B_{L} \tan \theta_{A}\right)-G_{L}^{2} \tan \theta_{A}}{\left(Y_{A}-B_{L} \tan \theta_{A}\right)^{2}+G_{L}^{2} \tan ^{2} \theta_{A}}$

here:

$G_{L}=1 / 50$

$B_{L}=Y_{5} \tan 30^{\circ}=Y_{5} / \sqrt{3}$

Once $Y_{5}$ is obtained, a simple modification can be made to facilitate $7^{\text {th }}$ harmonic component suppression by adding an open-circuit stub $\mathrm{TL}_{6}\left(Y_{6}, 12.9^{\circ}\right)$ in parallel with $\mathrm{TL}_{5}$, Fig. 4. For simplicity, we can assume $Y_{5 \_ \text {new }}=Y_{6}=Y_{\mathrm{C}}$ and its value 
can be calculated using the following formula.

$$
Y_{C}=\frac{Y_{5} \tan 30^{\circ}}{\tan 30^{\circ}+\tan 12.9^{\circ}} \approx 0.72 Y_{5}
$$

\section{DESIGN AND SIMUlation USING IDEAL COMPONENTS}

Design examples of the THP and FHP Class-EF PAs with enhanced $f_{\mathrm{MAX}}$ are now presented in order to better understand the theoretical analysis described in the previous sections. A dead time parameter $\tau_{\mathrm{D}}=48.5^{\circ}$ is chosen in order to obtain $P_{\text {MAX }} 35 \%$ higher than that of the Class-E as discussed in Section II. The results presented below were obtained from Keysight Advanced Design Systems (ADS) harmonic-balance simulations using ideal components, i.e., the transmission lines were assumed lossless, the transistor was modeled as a switch with $1 \mathrm{~m} \Omega$ ON resistance, $10 \mathrm{M} \Omega$ OFF resistance, and instantaneous switching time, and was driven by a sine wave.

\section{A. Third-harmonic-peaking Class-EF PA}

The design objectives are set as follows: $V_{\mathrm{DC}}=28 \mathrm{~V}$ and $P_{\mathrm{O}}=10 \mathrm{~W}$. The transistor which will be used in implementation is a CGH40010F GaN HEMT from CREE with $C_{\text {OUT }}=1.3 \mathrm{pF}$. Substituting these values into (5) results in $f_{\mathrm{MAX}}=0.5 \mathrm{GHz}$, meaning that the maximum frequency at which the original Class-EF PA in Fig. 1 can be effectively operated is only $0.5 \mathrm{GHz}$.

Consider now the circuit in Fig. 2. Given $f_{0}=2.5 \mathrm{GHz}$, the value of the shunt capacitance $C$ computed using (4) is 0.26 $\mathrm{pF}$. Since $C_{\mathrm{OUT}}=1.3 \mathrm{pF}$, the excess capacitance $C_{\mathrm{X}}\left(=C_{\mathrm{OUT}}-\right.$ $C$ ) required is $1.04 \mathrm{pF}$, implying $k=4$ i.e., $f_{\mathrm{MAX}}$ is increased from $0.5 \mathrm{GHz}$ to $2.5 \mathrm{GHz}$. The transmission-line parameter values $Z_{1}, \theta_{1}$, and $Z_{2}$ in Fig. 2(a) can be obtained by solving (8)-(10) simultaneously. $R$ and $L$ in (11) and (12) are computed using (2)-(3). The characteristic impedances $Z_{2 \mathrm{~A}}$ and $Z_{2 \mathrm{~B}}$ in Fig. 2(b) can be subsequently determined using (15) and when compared to $Z_{2}$ their values are higher. The value of $Z_{0}$ must be selected as high as the practical implementation will allow. Here it is set to $80 \Omega$ as values higher than this may result in an impractically narrow microstrip line. The optimal circuit component values are summarized in Table I. The simulated load impedances at the fundamental, second-, and third-harmonic frequencies, $Z_{\mathrm{OPT}}$, are plotted in Fig. 5. In accordance with (1)-(3), the Class-EF mode requirements for short- and open-circuit terminations at $2 f_{0}$ and $3 f_{0}$ respectively are met concurrently, as is the optimal impedance at $f_{0}$.

TABLE I

OPTIMAL CirCuit COMPONENT VALUES OF THE THIRD-HARMONIC-PEAKING CLASS-EF PA, FIG. 2 $(2.5 \mathrm{GHz}, 28 \mathrm{~V}, 10 \mathrm{~W})$

\begin{tabular}{|cc|cc|}
\hline$C$ & $0.26 \mathrm{pF}$ & $Z_{3}=Z_{4}$ & $80 \Omega$ \\
$C_{\mathrm{X}}$ & $1.04 \mathrm{pF}$ & $\theta_{1}$ & $69^{\circ}$ \\
$Z_{1}$ & $41 \Omega$ & $\theta_{2}=\theta_{2 \mathrm{~A}}$ & $30^{\circ}$ \\
$Z_{2}$ & $19 \Omega$ & $\theta_{2 \mathrm{~B}}$ & $18^{\circ}$ \\
$Z_{2 \mathrm{~A}}=Z_{2 \mathrm{~B}}$ & $29.8 \Omega$ & $\theta_{3}=\theta_{4}$ & $45^{\circ}$ \\
\hline
\end{tabular}

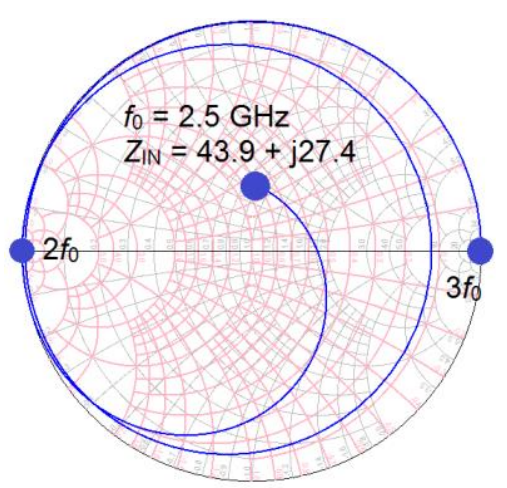

Frequency $(2.5 \mathrm{GHz}$ to $7.5 \mathrm{GHz})$

Fig. 5. Simulated load impedances of the THP Class-EF PA at fundamental, second, and third harmonic frequencies.

The effect that the parameter $k$ has on the circuit component values is studied in Fig. 6. As $k$ increases, the values of $Z_{2}$ and $\theta_{1}$ decrease whereas the value of $Z_{1}$ remains relatively flat up to $k=2$ above which it starts to descend. Intuitively, this can be explained as follows. At $3 f_{0}$, the shorted $\mathrm{TL}_{1}$ behaves like an inductance. This inductance must resonate with $C_{\mathrm{X}}$ so as to provide an open circuit. As $k$ (and accordingly $C_{\mathrm{X}}$ ) increases, the shorted $\mathrm{TL}_{1}$ needs to provide a smaller inductance so as to preserve the resonance at $3 f_{0}$. This is achieved through reduction of $Z_{1}$ or $\theta_{1},(8)$. At $k=2$, the value of $\theta_{1}$ has readily descended close to $60^{\circ}$ below which $\tan \left(3 \theta_{1}\right)$ in (8) would result in negative values, thereby violating (8). As a consequence, for $k>2$, the slope of $\theta_{1}$ in Fig. 6 needs to settle, and in order to compensate for this, $Z_{1}$ must be accordingly reduced.

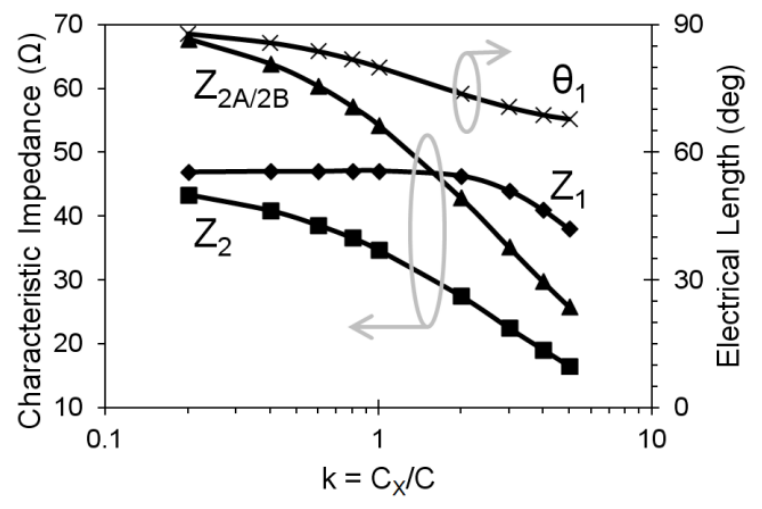

Fig. 6. Optimal transmission-line parameter values versus $k$ of the THP ClassEF PA.

The steady-state voltage and current waveforms of the circuits in Fig. 2 are illustrated in Fig. 7. As can be observed, the ZVS and ZVDS conditions are satisfied during the OFFto-ON transition. Further, consistent with the theory, the maximally flat peak switch voltage $\left(V_{\mathrm{SW}}\right)$ of $2 V_{\mathrm{DC}}=56 \mathrm{~V}$ is obtained. The currents through the switch and the capacitance $\mathrm{C}_{\text {OUT }}$ are denoted respectively as $I_{\mathrm{SW}}$ and $I_{\text {Cout }}$. Within the interval where $V_{\mathrm{SW}}$ is kept constant at $2 V_{\mathrm{DC}}, I_{\text {Cout }}$ is zero since $I_{\text {Cout }}$ is proportional to the first derivative of $V_{\mathrm{SW}}$. This distinctive feature differentiates the Class-EF PA from the 
Class-E PA in which $I_{\text {Cout }}$ has non-zero values throughout the OFF interval. Simulated output power and DC current are $39.76 \mathrm{dBm}$ and $340 \mathrm{~mA}$ leading to a drain efficiency of $99.5 \%$.
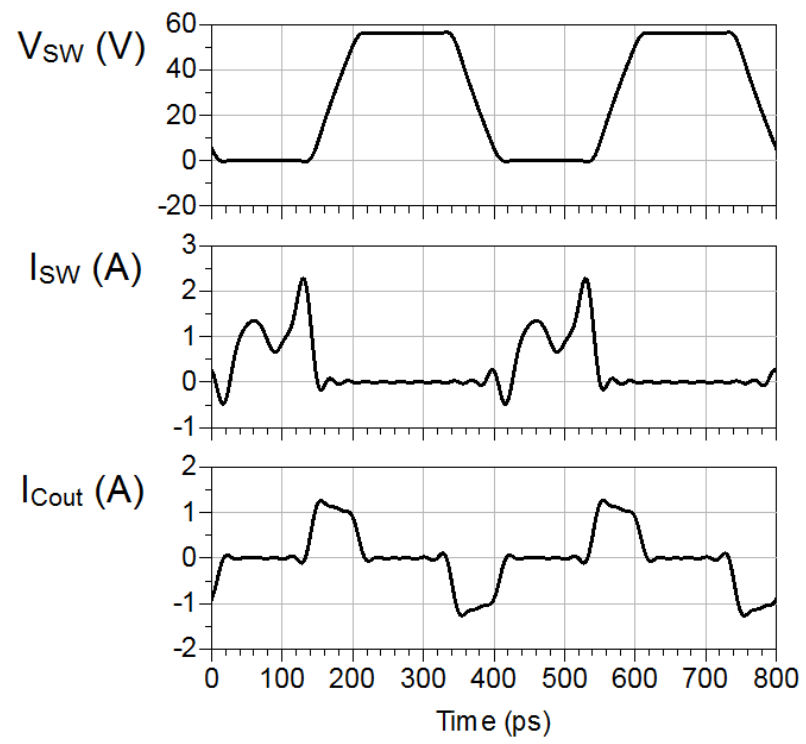

Fig. 7. Steady-state voltage and current waveforms of the THP Class-EF PA (Fig. 2), for $k=4$.

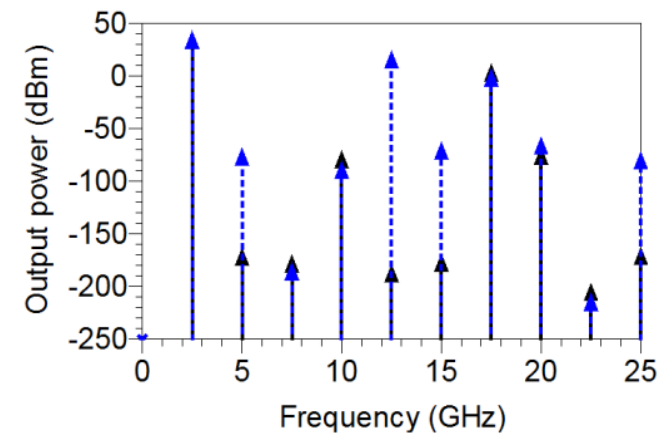

Fig. 8. Simulated output power spectrum of the THP Class-EF PA up to $10 f_{0}$ using ideal components: dotted lines for Fig. 2(a) and solid lines for Fig. 2(b).

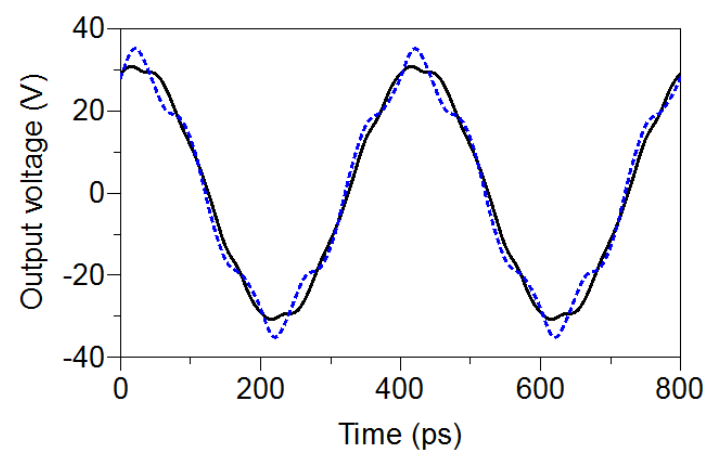

Fig. 9. Output voltage comparison: dotted lines for Fig. 2(a) and solid lines for Fig. 2(b).

Shown in Fig. 8 is the output power spectrum of the PA circuits in Figs. 2(a) and (b). Both PAs are able to deliver the fundamental output power level as specified earlier. $\mathrm{TL}_{2 \mathrm{~B}}$ adopted in Fig. 2(b) proves effective as a means to suppress the fifth-harmonic level. As a result, as can be seen from Fig. 9, the output voltage of the PA in Fig. 2(b) looks less distorted than that of Fig. 2(a). The second-, sixth-, and tenth-harmonic component levels of the PAs in Fig. 2(a) and (b) should theoretically be identical - discrepancies shown in Fig. 8 are mainly due to numerical artifacts in ADS.

\section{B. Fifth-Harmonic-Peaking Class-EF PA}

Consider now the circuit in Fig. 4. The design objectives are set as follows: $f_{0}=2 \mathrm{GHz}, V_{\mathrm{DC}}=28 \mathrm{~V}$ and $P_{\mathrm{O}}=13 \mathrm{~W}$. The value of the shunt capacitance $C$ computed using (4) is 0.42 $\mathrm{pF}$. Since $C_{\mathrm{OUT}}=1.3 \mathrm{pF}$, the excess capacitance $C_{\mathrm{X}}\left(=C_{\mathrm{OUT}}-\right.$ $C$ ) required is $0.88 \mathrm{pF}$, implying $k \approx 2$ i.e., $f_{\mathrm{MAX}}$ is increased from $647 \mathrm{MHz}$ to $2 \mathrm{GHz}$. Three parameters, i.e., $Y_{\mathrm{A}}, Y_{\mathrm{B}}$, and $Y_{\mathrm{C}}$ are to be determined. First, the characteristic admittance of $\mathrm{TL}_{1}$ and $\mathrm{TL}_{4}$ i.e., $Y_{\mathrm{A}}$ is computed from either (22) or (30) where the value of $\theta_{1}=\theta_{4}$ is given in (32). By simultaneously solving (33) and (34), the values of $Y_{\mathrm{B}}$ and $Y_{5}$ can be obtained, and subsequently the value of $Y_{\mathrm{C}}$ is calculated using (43). The optimal circuit component values are summarized in Table II. The simulated load impedances at fundamental and higher harmonic frequencies (up to $5 f_{0}$ ), $Z_{\mathrm{OPT}}$, are plotted in Fig. 10 . In accordance with (1)-(3), the Class-EF mode requirements for short- and open-circuit terminations at even and odd harmonics respectively are satisfied, and so is the optimal impedance at $f_{0}$.

TABLE II

OPTIMAL CiRCUIT COMPONENT VALUES OF THE FIFTH-HARMONIC-PEAKING Class-EF PA, Fig. 4 $(2 \mathrm{GHz}, 28 \mathrm{~V}, 13 \mathrm{~W})$

\begin{tabular}{|cc|cc|}
\hline$C$ & $0.42 \mathrm{pF}$ & $\theta_{0}$ & $45^{\circ}$ \\
$C_{\mathrm{X}}$ & $0.88 \mathrm{pF}$ & $\theta_{1}=\theta_{4}$ & $11.5^{\circ}$ \\
$Z_{0}$ & $80 \Omega$ & $\theta_{2}$ & $18^{\circ}$ \\
$Z_{1}=Z_{4}$ & $23.9 \Omega$ & $\theta_{3}$ & $12^{\circ}$ \\
$Z_{2}=Z_{3}$ & $71.7 \Omega$ & $\theta_{5}$ & $30^{\circ}$ \\
$Z_{5}=Z_{6}$ & $33.2 \Omega$ & $\theta_{6}$ & $12.9^{\circ}$ \\
\hline
\end{tabular}

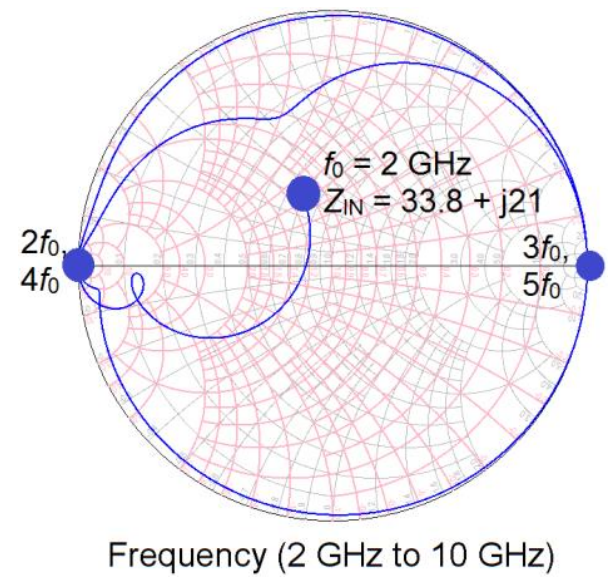

Fig. 10. Simulated load impedances of the FHP Class-EF PA at fundamental and higher harmonic frequencies.

The steady-state voltage and current waveforms are illustrated in Fig. 11. Simulated output power is $12.9 \mathrm{~W}$ and simulated DC current is $461 \mathrm{~mA}$, leading to a drain efficiency 
of $99.9 \%$. The output power spectrum of the PA circuit in Fig. 4 is shown in Fig. 12 where harmonics up to the $10^{\text {th }}$ are well suppressed. The $2^{\text {nd }}, 6^{\text {th }}$, and $10^{\text {th }}$ harmonic components are suppressed through short-circuit termination facilitated by the $\lambda / 8$ open-circuit stub. The $4^{\text {th }}$ and $8^{\text {th }}$ harmonic components are suppressed by means of short-circuit termination facilitated by the $\lambda / 8$ shorted stub. The $3^{\text {rd }}$ and $5^{\text {th }}$ harmonic components are suppressed through open-circuit termination facilitated by the PA's load network i.e., $C_{\mathrm{X}}, \mathrm{TL}_{1}-\mathrm{TL}_{6}$, and $\lambda / 8$ open-circuit and shorted stubs. $\mathrm{TL}_{6}$ is responsible for providing a short-circuit termination to the $7^{\text {th }}$ harmonic component. As a result, the PA produced a nearly pure sine wave at the output $\left(V_{\mathrm{O}}\right)$, Fig. 11.
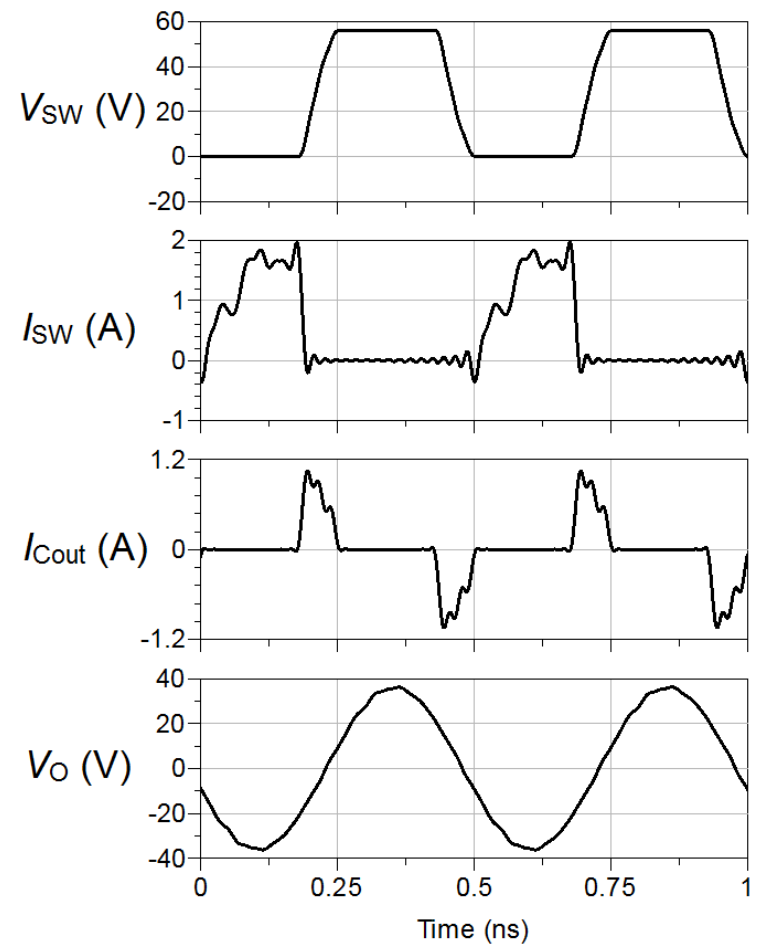

Fig. 11. Steady-state voltage and current waveforms of the FHP Class-EF PA (Fig. 4).

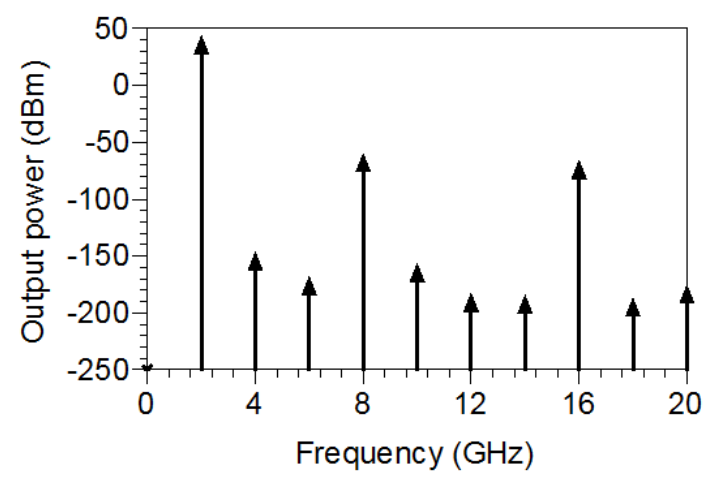

Fig. 12. Simulated output power spectrum of the FHP Class-EF PA up to $10 f_{0}$ using ideal components.

\section{IMPLEMENTATION AND MEASUREMENT}

In order to validate the theoretical synthesis approach in Section III, we fabricated a test board, Fig. 13(a). This comprised of a $\lambda / 8$ open-circuit stub, a $\lambda / 8$ shorted stub, and a
$50 \Omega$ series TL which connects the input and output ports. The characteristic impedance of the stubs is $80 \Omega$. The physical dimensions of the stubs are $W=0.46 \mathrm{~mm}$ and $L=9.34 \mathrm{~mm}$. For comparison, another test board comprised of a $\lambda / 4 \mathrm{TL}$ ( $W=0.46 \mathrm{~mm}$ and $L=18.68 \mathrm{~mm}$ ) was built, Fig. 13(b). The measured and simulated frequency responses of the stubs at $f_{0}=2.5 \mathrm{GHz}$ and higher harmonics are compared with the $\lambda / 4$ TL in Fig. 13(c). It can be observed that the rejection band $(|\mathrm{S} 21| \leq-10 \mathrm{~dB})$ of the proposed arrangement is as predicted i.e., twice as wide as the $\lambda / 4$ TL.

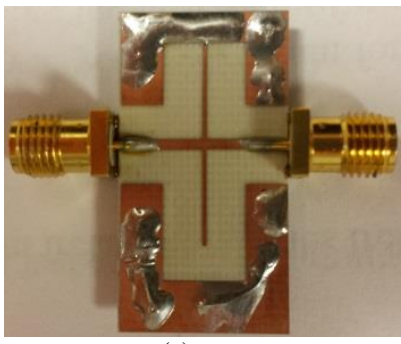

(a)

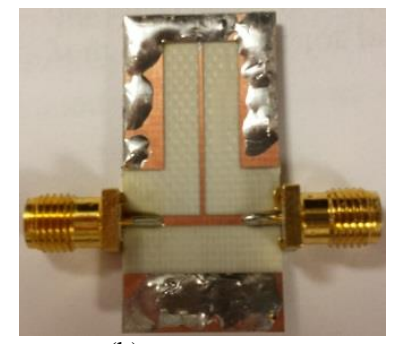

(b)

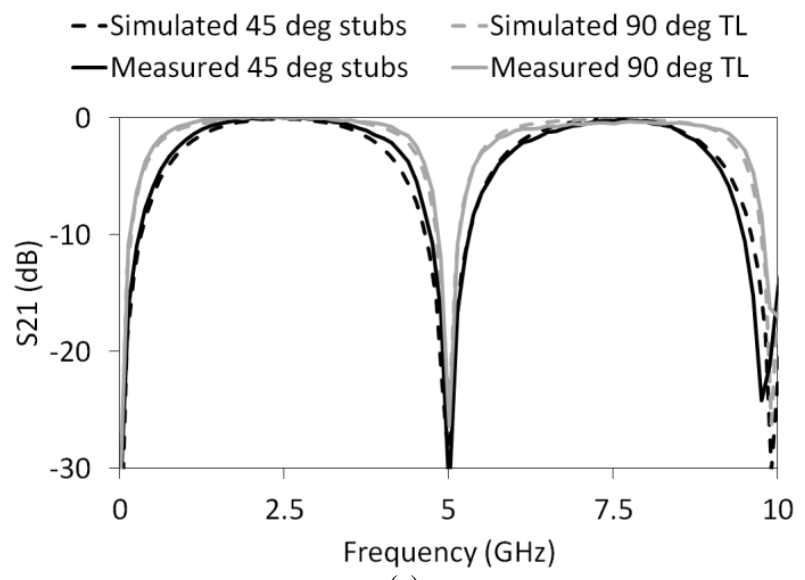

(c)

Fig. 13. (a) Test board of the proposed $\lambda / 8$ stubs, (b) test board of the traditional $\lambda / 4 \mathrm{TL}$, and (c) measured and simulated frequency responses.

For the validation of the THP and FHP Class-EF PAs analysis described in Sections III and IV, two prototypes were built. The PAs employ packaged GaN HEMTs CGH40010F from CREE with drain-source breakdown voltage of $120 \mathrm{~V}$ and typical saturated power of $13 \mathrm{~W}$. The manufacturer datasheet shows that the transistor is potentially unstable at frequencies below $3.5 \mathrm{GHz}$ and therefore stabilizing resistors are needed. The PAs were realized on a $0.5-\mathrm{mm}$ thick Rogers RO4003C substrate with dielectric constant of 3.55, loss tangent of 0.0027 , and thermal conductivity of $0.71 \mathrm{~W} / \mathrm{m} /{ }^{\circ} \mathrm{K}$.

\section{A. Third-Harmonic-Peaking Class-EF PA}

The circuit component values were initially obtained by converting the characteristic impedance $\left(Z_{\mathrm{N}}\right)$ and electrical length $\left(\theta_{\mathrm{N}}\right)$ values given in Table $\mathrm{I}$ into the corresponding microstrip physical dimensions in terms of width $\left(W_{N}\right)$ and length $\left(L_{N}\right)$. These values were then optimized in the simulation in order to give best performances in terms of efficiency, output power and harmonic suppression levels. 


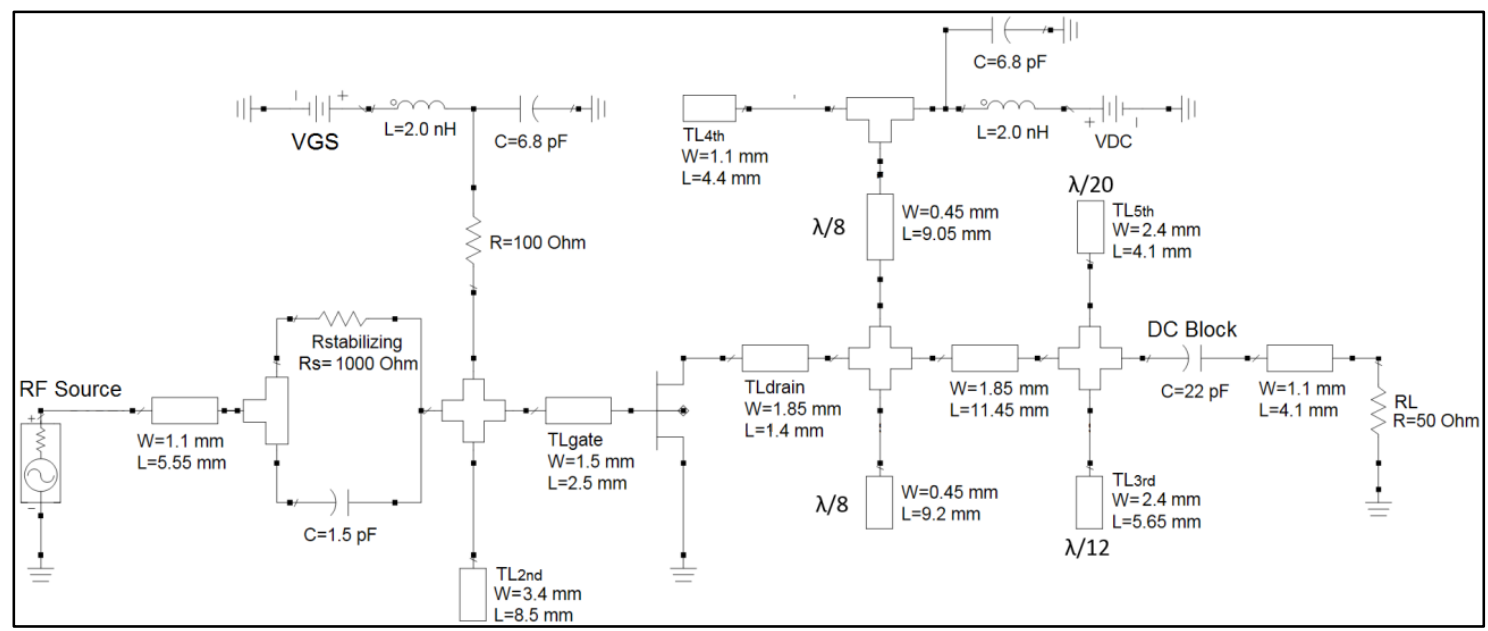

Fig. 14. Complete circuit schematic of the THP Class-EF PA.

TABLE III

TRANSMISSION-LINE LOAD-NETWORK PARAMETER VALUES OF THE THIRD-HARMONIC-PEAKING ClASS-EF PA, Fig. 2(b) $(2.5 \mathrm{GHz}, 28 \mathrm{~V}, 10 \mathrm{~W})$

\begin{tabular}{|c|c|c|}
\hline Parameter & $\begin{array}{c}\text { Theoretical } \\
\text { Values } \\
(\mathrm{mm})\end{array}$ & $\begin{array}{c}\text { Optimized } \\
\text { Values } \\
(\mathrm{mm})\end{array}$ \\
\hline$W_{1}$ & 1.52 & 1.85 \\
$L_{1}$ & 13.64 & 11.45 \\
$W_{2 \mathrm{~A}}$ & 2.38 & 2.4 \\
$L_{2 \mathrm{~A}}$ & 5.81 & 5.65 \\
$W_{2 \mathrm{~B}}$ & 2.38 & 2.4 \\
$L_{2 \mathrm{~B}}$ & 3.49 & 4.1 \\
$W_{3}=W_{4}$ & 0.46 & 0.45 \\
$L_{3}$ & 9.34 & 9.05 \\
$L_{4}$ & 9.34 & 9.2 \\
\hline \multicolumn{2}{|r}{}
\end{tabular}

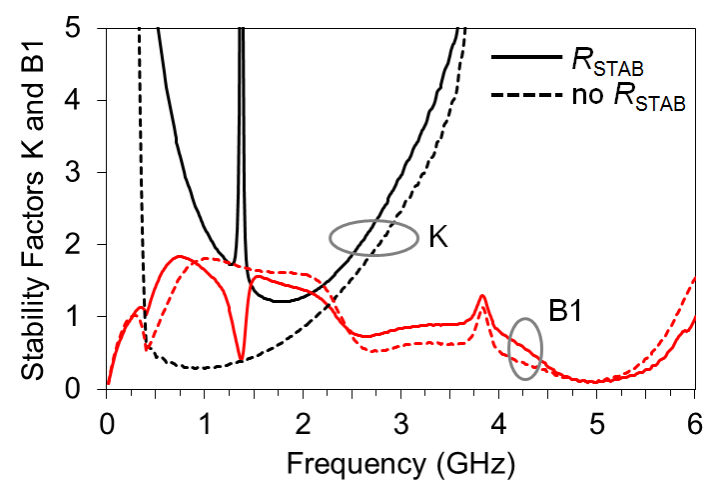

Fig. 15. Simulated stability factors $\mathrm{K}$ and $\mathrm{B} 1$ before and after adding a stabilizing parallel resistor of $1 \mathrm{k} \Omega$ at the input.

The theoretical and optimized circuit component values are presented in Table III.

The complete circuit schematic of the THP Class-EF PA which includes the input matching network, biasing and stabilizing circuits is illustrated in Fig. 14. A $6.8 \mathrm{pF}$ capacitor is used as an $\mathrm{RF}$ bypass capacitance as it presents low impedance at the fundamental frequency. The input matching circuit consists of a $1.5 \mathrm{pF}$ series capacitance and an opencircuit stub $\left(\mathrm{TL}_{2 \mathrm{nd}}\right)$. A $1 \mathrm{k} \Omega$ resistor connected in parallel with the $1.5 \mathrm{pF}$ capacitance is used to make the PA unconditional stable i.e., $K$ is larger than 1 and $B_{1}$ is larger than 0, Fig. 15 . The photograph of the PA prototype with a square dimension of $4.2 \mathrm{~cm} \times 4.2 \mathrm{~cm}$ is depicted in Fig. 16 .

As depicted in Fig. 17, a Keysight E8257D signal generator was used to excite the amplifier with a continuous-wave $(\mathrm{CW})$ signal and the output power was measured using Keysight N9320A spectrum analyzer. Since the maximum output power of the signal generator was limited to $17 \mathrm{dBm}$, an identical replica of the amplifier was used as a driver. A 20-dB attenuator was inserted between the PA and the spectrum analyzer. Gate and drain biasing was applied using Thurlby Thandar power supplies (32 V - 3 A).

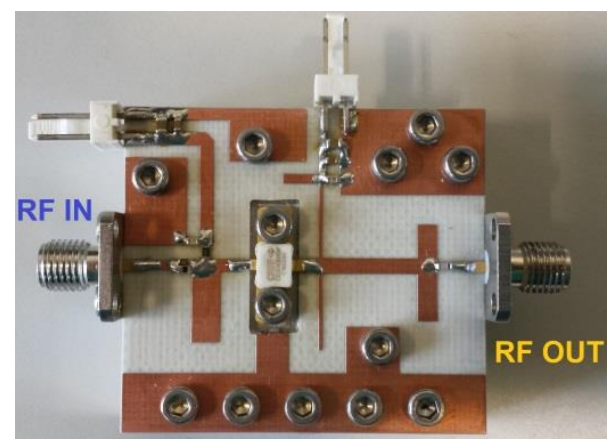

Fig. 16. The THP Class-EF PA prototype.

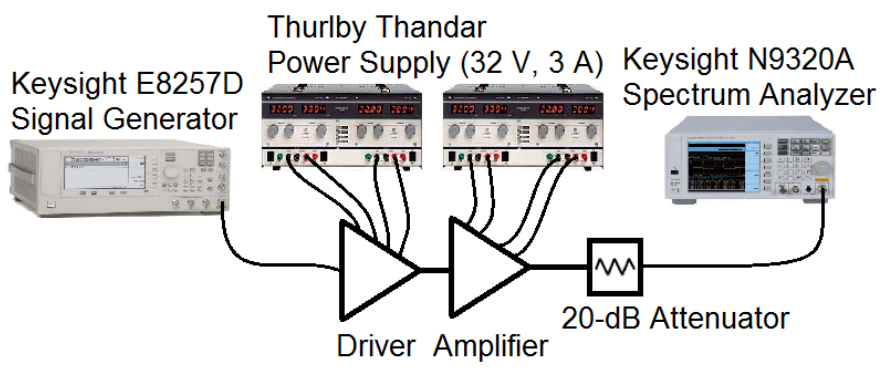

Fig. 17. Measurement setup.

Fig. 18 shows measured output power, gain, drain efficiency and PAE versus input power at $2.22 \mathrm{GHz}$ with $V_{\mathrm{GS}}=-2.7 \mathrm{~V}$ and $V_{\mathrm{DC}}=28 \mathrm{~V}$. Best efficiency performance 
i.e., when drain efficiency and PAE peaked at $91 \%$ and $80 \%$ respectively was achieved at output power of $39.5 \mathrm{dBm}$ and gain of $9.2 \mathrm{~dB}$. At this operating point, $350 \mathrm{~mA}$ DC current was drawn from the power supply.

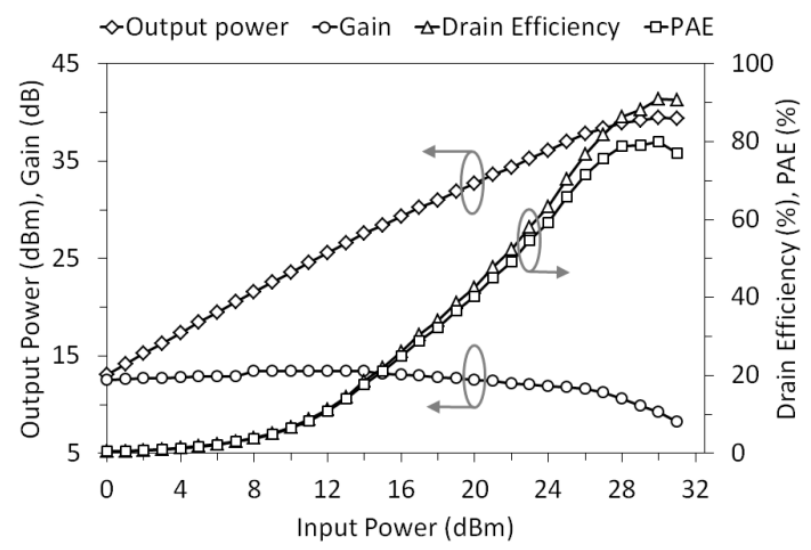

Fig. 18. Measured PA performances versus input power at $2.22 \mathrm{GHz}$ with $V_{\mathrm{DC}}=28 \mathrm{~V}$ and $V_{\mathrm{GS}}=-2.7 \mathrm{~V}$.

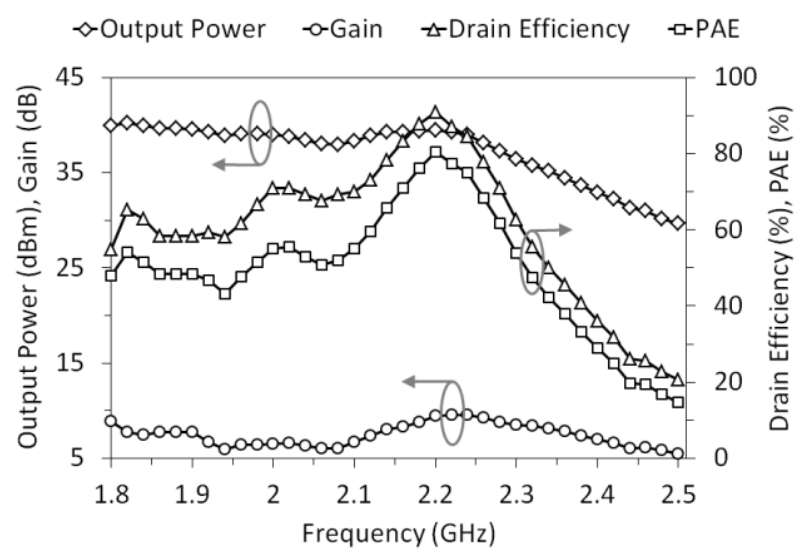

Fig. 19. Measured PA performances versus frequency at $V_{\mathrm{DC}}=28 \mathrm{~V}$ and $V_{\mathrm{GS}}=-2.7 \mathrm{~V}$.

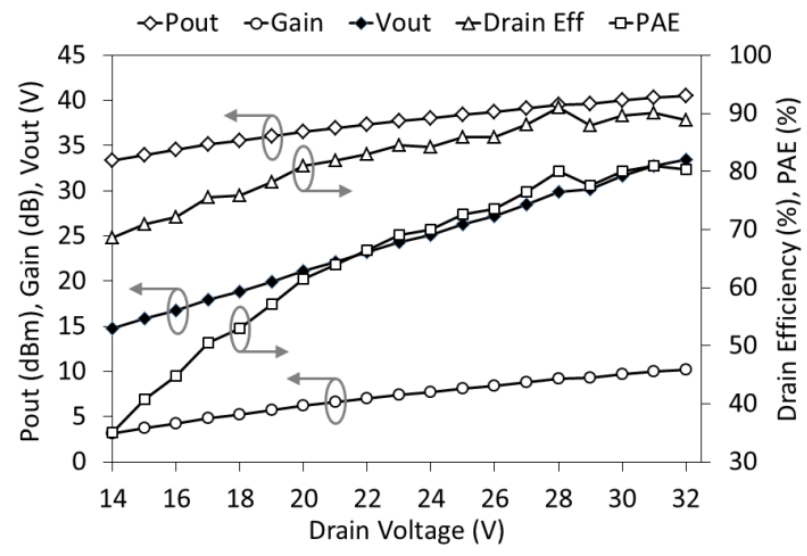

Fig. 20. Measured PA performances versus $V_{\mathrm{DC}}$ at $2.22 \mathrm{GHz}$ with $V_{\mathrm{GS}}=-2.7$ V.

The frequency behavior of the PA is illustrated in Fig. 19. Within $460 \mathrm{MHz}$ frequency range i.e., from 1.82 to $2.28 \mathrm{GHz}$, the PA was able to deliver $38.8 \pm 1.5 \mathrm{dBm}$ output power with drain efficiency of at least 58\%. PA performance at $2.22 \mathrm{GHz}$ when the supply voltage $V_{\mathrm{DC}}$ was swept is shown in Fig. 20 . Results show that drain efficiency and PAE remained above $81 \%$ and $62 \%$ respectively when $V_{\mathrm{DC}}$ was varied from 20 to 32 V. Fig. 20 also shows a near linear relationship between output voltage and $V_{\mathrm{DC}}$. This feature is useful for effective deployment of the PA in envelope elimination and restoration (EER) systems or polar transmitters. By decreasing $V_{\mathrm{DC}}$ from 28 to $14 \mathrm{~V}$, the output power was reduced by around $6 \mathrm{~dB}$ from 39.5 to $33.4 \mathrm{dBm}$, within which range the drain efficiency remained above 68\%. Simulated output power spectrum is shown in Fig. 21.

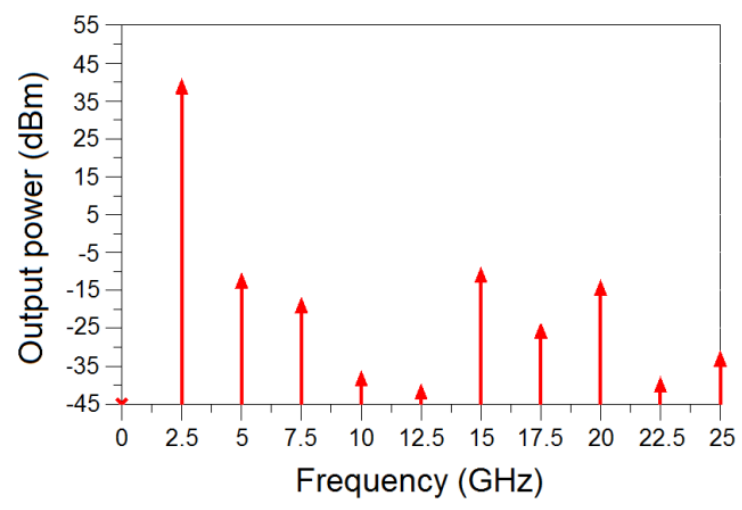

Fig. 21. Simulated output power spectrum of the THP Class-EF PA.

\section{B. Fifth-Harmonic-Peaking Class-EF PA}

Initial circuit component values were obtained by converting the characteristic impedance $\left(Z_{\mathrm{N}}\right)$ and electrical length $\left(\theta_{\mathrm{N}}\right)$ values given in Table II into the corresponding microstrip physical dimensions i.e., width $\left(W_{\mathrm{N}}\right)$ and length $\left(L_{\mathrm{N}}\right)$. These values were then optimized in the simulation in order to give best performances in terms of efficiency, output power and harmonic suppression levels. The theoretical and optimized component values are presented in Table IV.

TABLE IV

TRANSMISSION-LINE LOAD-NETWORK PARAMETER VALUES OF THE FIFTH-HARMONIC-PEAKING ClaSs-EF PA, FIG. 4 $(2 \mathrm{GHz}, 28 \mathrm{~V}, 13 \mathrm{~W})$

\begin{tabular}{|c|c|c|}
\hline Parameter & $\begin{array}{c}\text { Theoretical } \\
\text { Values }(\mathrm{mm})\end{array}$ & $\begin{array}{c}\text { Optimized } \\
\text { Values }(\mathrm{mm})\end{array}$ \\
\hline$W_{1}=W_{4}$ & 3.17 & 3.17 \\
$L_{1}=L_{4}$ & 2.75 & 2.75 \\
$W_{2}=W_{3}$ & 0.58 & 0.58 \\
$L_{2}$ & 4.63 & 4.5 \\
$L_{3}$ & 3.09 & 3.09 \\
$W_{5}=W_{6}$ & 2.06 & 2.06 \\
$L_{5}$ & 7.31 & 7.45 \\
$L_{6}$ & 3.13 & 3 \\
$W_{0}$ & 0.46 & 0.46 \\
$L_{0}$ short & 11.67 & 10.5 \\
$L_{0}$ open & 11.67 & 11.5 \\
\hline
\end{tabular}

The circuit schematic of the FHP Class-EF PA is shown in Fig. 22. The PA employs a simple L-type input matching network comprised of a series capacitance $1.8 \mathrm{pF}$ and a 6.05$\mathrm{mm}$-long shorted stub. Due to high quality factor $(Q)$ of the 
This is the author's version of an article that has been published in this journal. Changes were made to this version by the publisher prior to publication. The final version of record is available at http://dx.doi.org/10.1109/TMTT.2014.2386327

IEEE Transactions on Microwave Theory and Techniques

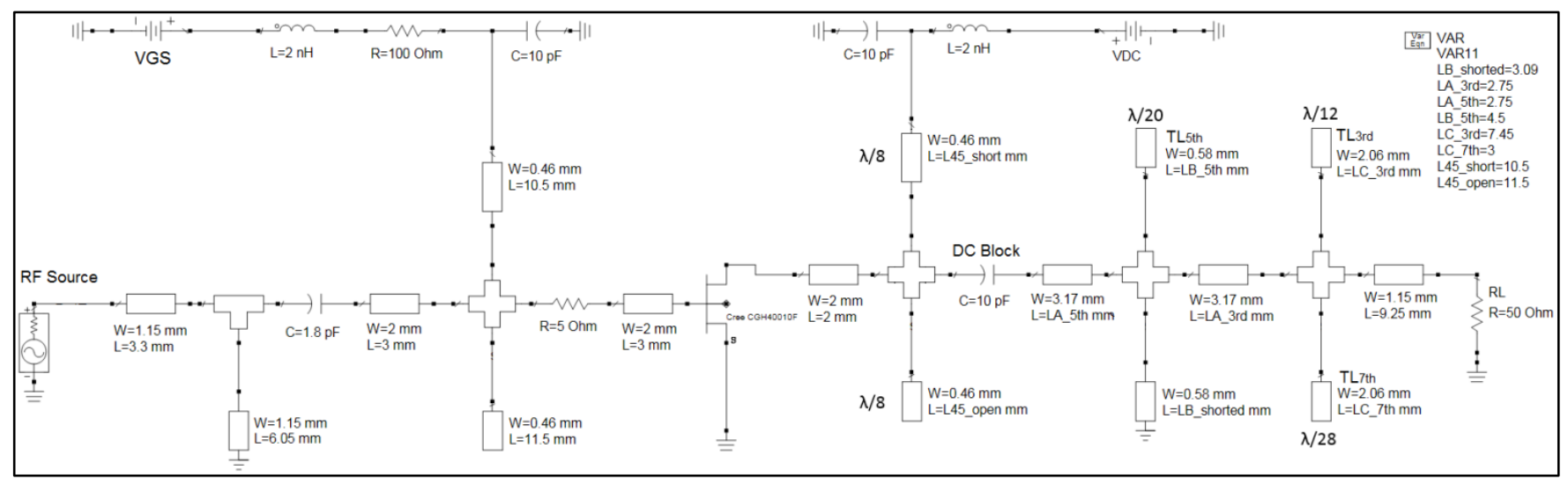

Fig. 22. Complete circuit schematic of the FHP Class-EF PA.

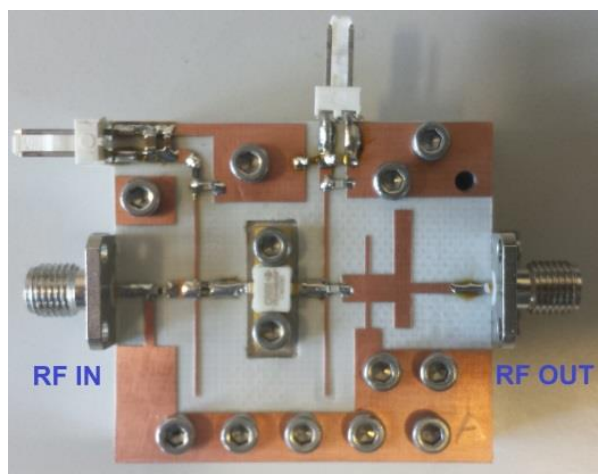

Fig. 23. The FHP Class-EF PA prototype.

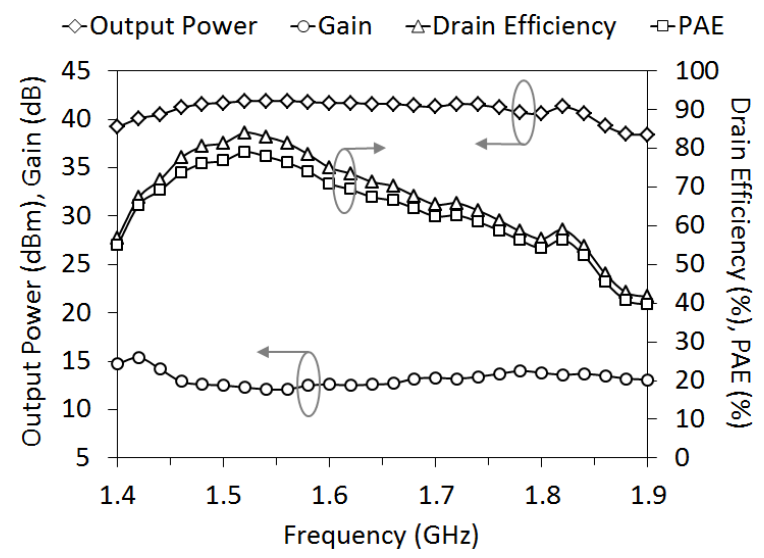

Fig. 24. Measured PA performances versus frequency at $V_{\mathrm{DC}}=32 \mathrm{~V}$ and $V_{\mathrm{GS}}=-2.8 \mathrm{~V}$.

complex load network, the FHP Class-EF PA circuit tends to be more sensitive to instability than the THP Class-EF PA. Consequently, a $5-\Omega$ series resistance connected to the transistor's gate was required in order to prevent oscillation, but this comes at the expense of increased power loss. The prototype measures $4 \mathrm{~cm} \times 4 \mathrm{~cm}$, Fig. 23 .

Measured PA performances in terms of output power, gain, drain efficiency and PAE at $V_{\mathrm{DC}}=32 \mathrm{~V}$ and $V_{\mathrm{GS}}=-2.8 \mathrm{~V}$ are plotted against frequency in Fig. 24. Across a $300 \mathrm{MHz}$ frequency range from 1.42 to $1.72 \mathrm{GHz}$, the PA delivered output power $>40 \mathrm{dBm}$ with drain efficiency $>65 \%$ and PAE $>62 \%$. Plotted in Fig. 25 are the measured PA performances

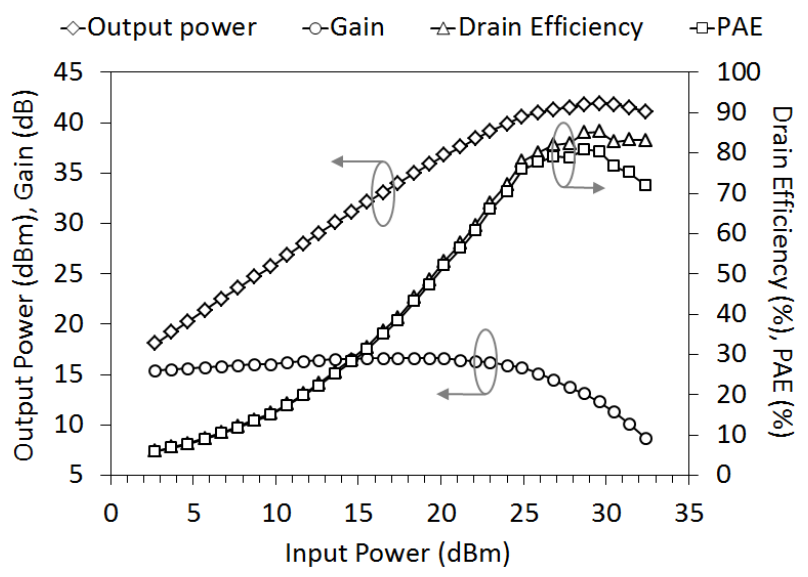

Fig. 25. Measured PA performances versus input power at $1.52 \mathrm{GHz}$ with $V_{\mathrm{DC}}=32 \mathrm{~V}$ and $V_{\mathrm{GS}}=-2.8 \mathrm{~V}$.

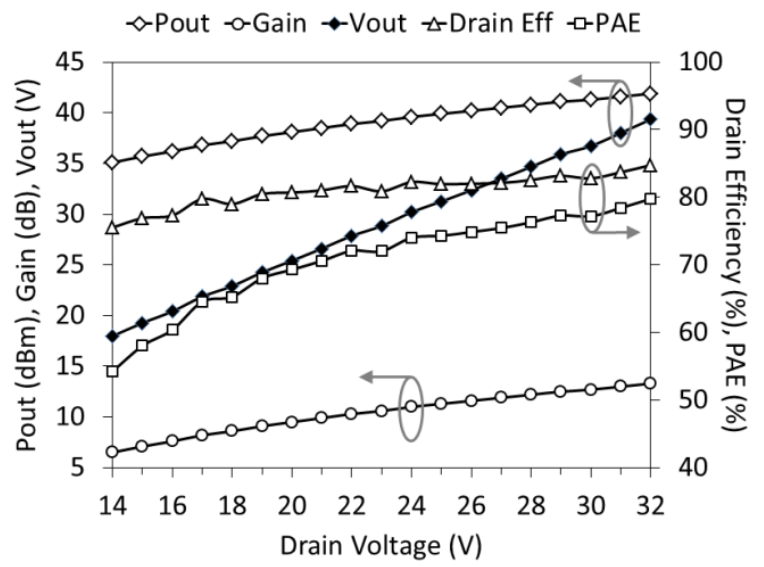

Fig. 26. Measured PA performances versus $V_{\mathrm{DC}}$ at $1.52 \mathrm{GHz}$.

versus input power at $1.52 \mathrm{GHz}$. Peak drain efficiency of $85 \%$ and peak PAE of $81 \%$ were achieved at $41.9 \mathrm{dBm}$ output power and $13.1 \mathrm{~dB}$ gain. The efficiency is lower than that of the THP Class-EF PA partly due to the 5- $\Omega$ series resistor used to stabilize the PA (as opposed to the $1-\mathrm{k} \Omega$ parallel resistor used in the THP Class-EF PA). The linear gain was about $16 \mathrm{~dB}$. Fig. 26 shows the PA's behavior when the supply voltage was varied. Also shown in Fig. 26 is a near linear relationship between output voltage and $V_{\mathrm{DC}}$. By 
decreasing $V_{\mathrm{DC}}$ from 32 to $14 \mathrm{~V}$, the output power was reduced by $6.8 \mathrm{~dB}$ from 41.9 to $35.1 \mathrm{dBm}$, within which range the drain efficiency of at least $75 \%$ was achieved. Simulated output power spectrum is shown in Fig. 27.

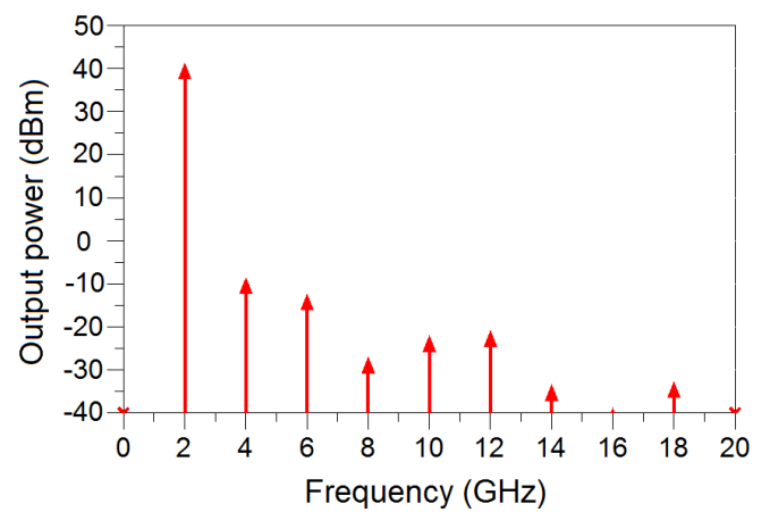

Fig. 27. Simulated output power spectrum of the FHP Class-EF PA.

\section{Measurement Vs. Simulation}

The THP Class-EF PA was designed to operate at $2.5 \mathrm{GHz}$. However, as can be seen from Fig. 28(a), the measured frequency shifted to a lower frequency, around $2.2 \mathrm{GHz}$. This disagreement is mainly due to the fact that the transistor model provided by the manufacturer does not incorporate packaged lead inductances at the gate and drain. When these inductances are included in the model, the simulation agrees pretty well with the measurement result, Fig. 28(b). The same applies to the FHP Class-EF PA where the design frequency is $2 \mathrm{GHz}$ and measured frequency is $1.5 \mathrm{GHz}$, Fig. 29. The performances of the proposed PAs when compared to other published results are summarized in Table V. When compared with other PAs employing GaN HEMTs and operating at frequencies around $2-2.5 \mathrm{GHz}$ [27]-[31], the THP Class-EF PA exhibits the highest drain efficiency and PAE at a comparable output power. The output power, drain efficiency, and PAE performances of the $1.52 \mathrm{GHz}$ FHP Class-EF PA are superior to those of the $1.0 \mathrm{GHz}$ PAs reported in [23]-[25].

\section{CONCLUSION}

The analysis and design of THP and FHP Class-EF PAs including a method to increase their maximum operating frequency has been presented. These PAs employed a novel $\lambda / 8$ open-circuit and shorted stub arrangement which facilitates improved even-harmonic suppression and therefore yields high efficiency. Since the FHP PA satisfies the Class$\mathrm{EF}$ open-circuit load impedance requirement at not only $3 f_{0}$ but also $5 f_{0}$, its DC to RF efficiency is theoretically higher than that of the THP PA. However, in practice this might not be the case since the load network of the FHP PA is more sophisticated (thus more lossy), and prone to instability which in turn will degrade PA efficiency due to additional loss introduced by a stabilizing circuit.

The validity of the analytical derivation has been confirmed through harmonic-balance simulation and by measurement. Two PA prototypes were built using GaN HEMTs. The THP
Class-EF PA delivered $39.5 \mathrm{dBm}$ output power with $80 \%$ PAE at $2.22 \mathrm{GHz}$. Measured peak PAE of $81 \%$ and output power of $41.9 \mathrm{dBm}$ were obtained at $1.52 \mathrm{GHz}$ for the FHP Class-EF PA.

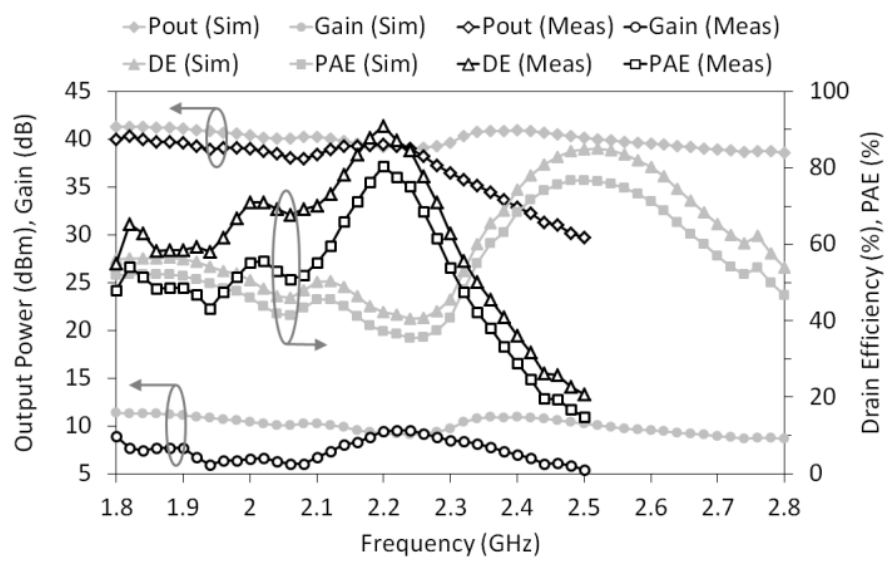

(a)

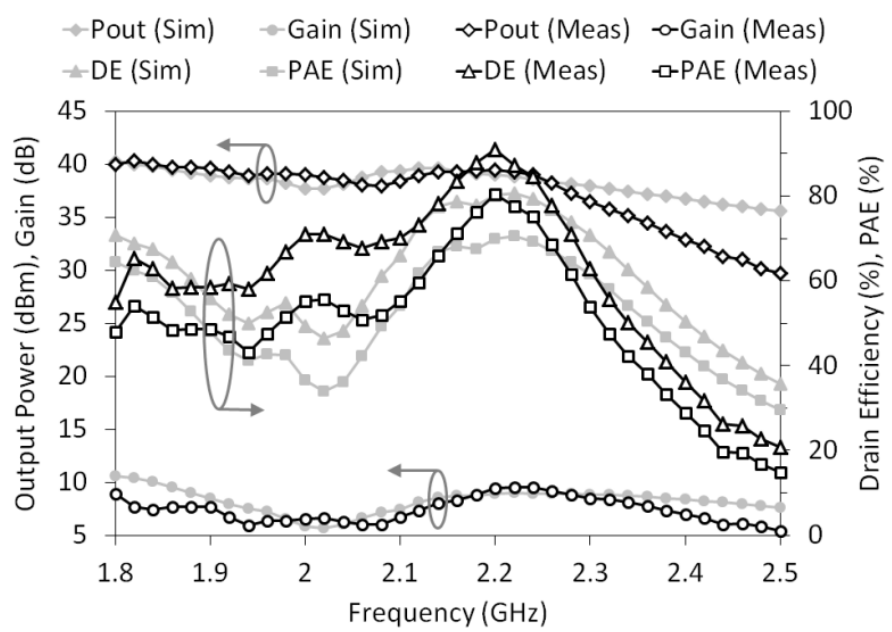

(b)

Fig. 28. Measured performances of the THP Class-EF PA compared with simulation results using: (a) original transistor model and (b) modified transistor model.

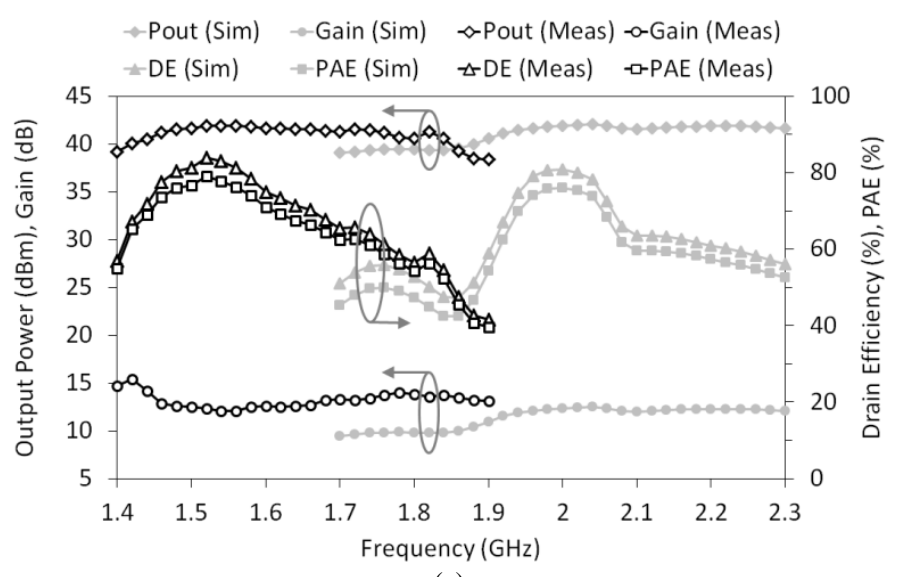

(a) 
This is the author's version of an article that has been published in this journal. Changes were made to this version by the publisher prior to publication. The final version of record is available at http://dx.doi.org/10.1109/TMTT.2014.2386327

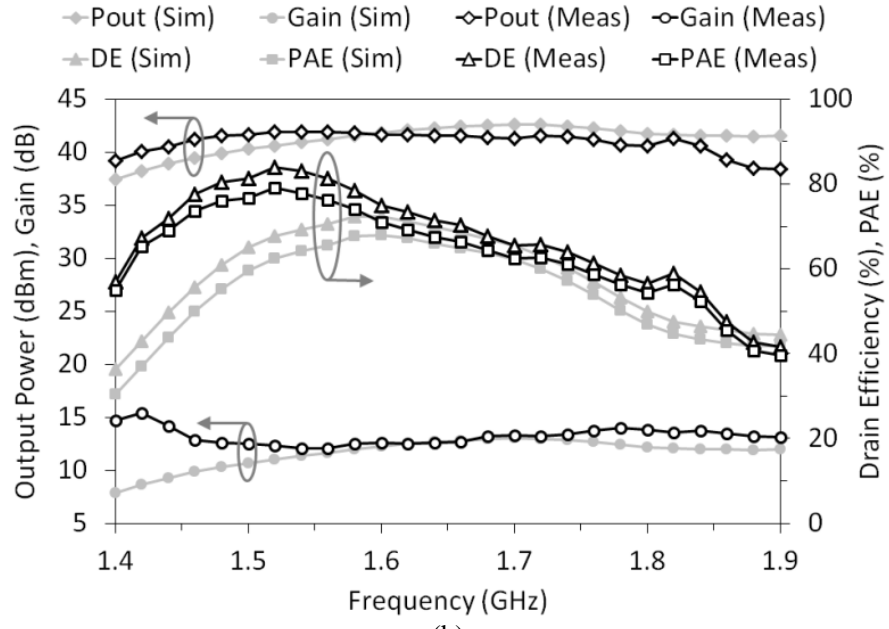

(b)

Fig. 29. Measured performances of the FHP Class-EF PA compared with simulation results using: (a) original transistor model and (b) modified transistor model.

TABLE V

PERFORMANCES SUMMARY AND COMPARISONS WITH OTHER PAS WITH OUTPUT POWER $\geq 2 \mathrm{~W}$

\begin{tabular}{|c|c|c|c|c|c|c|}
\hline Ref. & $\begin{array}{c}\text { Freq. } \\
(\mathrm{MHz})\end{array}$ & $\begin{array}{c}\text { Pout } \\
(\mathrm{dBm})\end{array}$ & $\begin{array}{c}\eta \\
(\%)\end{array}$ & $\begin{array}{c}\text { PAE } \\
(\%)\end{array}$ & $\begin{array}{c}\text { Gain } \\
(\mathrm{dB})\end{array}$ & $\begin{array}{c}\mathrm{V}_{\mathrm{DC}} \\
(\mathrm{V})\end{array}$ \\
\hline$[22]^{1}$ & 61.44 & 33.7 & 86.6 & 85.7 & 19.7 & 10 \\
\hline$[23]$ & 1000 & 37 & 78.8 & 77.7 & 18.5 & 25 \\
\hline$[24]$ & 1000 & 39.8 & 77.5 & 74.2 & 13.7 & 28 \\
\hline$[25]$ & 1000 & 39.7 & 83.1 & 81.3 & 15.9 & 46 \\
\hline$[26]^{1}$ & 1000 & 41.5 & 76.7 & 75 & 16.5 & 50 \\
\hline$[27]$ & 2000 & 40.7 & 84.6 & 80.1 & 12.7 & 28 \\
\hline$[28]$ & 2140 & 40 & 76 & 73.1 & 14.3 & 30 \\
\hline$[29]$ & 2140 & 37 & 73 & 70 & 15 & 25 \\
\hline$[30]$ & 2450 & 39.4 & - & 71.2 & - & 28 \\
\hline$[31]$ & 2500 & 38.3 & 79 & 74 & 12 & 28 \\
\hline$[32]^{2}$ & 2550 & 34.7 & 72 & 64 & 9.5 & 8 \\
\hline$[33]$ & 3100 & 40 & 85 & 82 & 15 & 28 \\
\hline$[34]$ & 3475 & 38.4 & 83.1 & 80.1 & 14.4 & 28 \\
\hline$[35]$ & 3500 & 40.4 & 82 & 78 & 12 & 28 \\
\hline THP PA & $\mathbf{2 2 2 0}$ & $\mathbf{3 9 . 5}$ & $\mathbf{9 1}$ & $\mathbf{8 0}$ & $\mathbf{9 . 2}$ & $\mathbf{2 8}$ \\
\hline FHP PA & $\mathbf{1 5 2 0}$ & $\mathbf{4 1 . 9}$ & $\mathbf{8 5}$ & $\mathbf{8 1}$ & $\mathbf{1 3 . 1}$ & $\mathbf{3 2}$ \\
\hline
\end{tabular}

${ }^{1}$ LDMOS, ${ }^{2}$ GaAs pHEMT, otherwise GaN HEMT

\section{REFERENCES}

[1] S. C. Cripps, RF Power Amplifiers for Wireless Communications. Norwood, MA: Artech House, Inc., 2006.

[2] N. O. Sokal and A. D. Sokal, "Class E - A new class of high-efficiency tuned single-ended switching power amplifiers," IEEE. J. Solid-State Circuits, vol. 10, no. 3, pp. 168-176, Jun. 1975.

[3] F. H. Raab, "Idealized operation of the Class E tuned power amplifier," IEEE Trans. Circuits Syst., vol. 24, no. 12, pp. 725-735, Dec. 1977.

[4] M. Thian, V. Fusco, and P. Gardner, "Power-combining Class-E amplifier with finite choke," IEEE Trans. Circuits Syst. I, Reg. Papers, vol. 58, no. 3, pp. 451-457, Mar. 2011.

[5] T. Mury and V. Fusco, "Exploring figures of merit associated with the suboptimum operation of Class-E power amplifiers," IET Circuits Devices Syst., vol. 1, no. 6, pp. 401-407, Dec. 2007.

[6] T. Mury and V. F. Fusco, "Series-L/parallel-tuned comparison with shunt-C/series-tuned Class-E power amplifier," IEE Circuits Devices Syst., vol. 152, no. 6, pp. 709-717, Dec. 2005.

[7] T. Mury and V. F. Fusco, "Sensitivity characteristics of Inverse Class-E power amplifier," IEEE Trans. Circuits Syst. I, Reg. Papers, vol. 54, no. 4, pp. 768-778, Apr. 2007.
[8] T. Mury and V. Fusco, "Inverse Class-E amplifier with transmission-line harmonic suppression," IEEE Trans. Circuits Syst. I, Reg. Papers, vol. 54, no. 7, pp. 1555-1561, Jul. 2007.

[9] F. H. Raab, "Class-F power amplifiers with maximally flat waveforms," IEEE Trans. Microwave Theory Techn., vol. 45, no. 11, pp. 2007-2012, Nov. 1997.

[10] M. D. Weiss, F. H. Raab, and Z. Popovic, "Linearity of X-band Class-F power amplifiers in high-efficiency transmitters," IEEE Trans. Microwave Theory Techn., vol. 49, no. 6, pp. 1174-1179, Jun. 2001.

[11] K. W. Eccleston, "Modified Class-F distributed amplifier," IEEE Microw. Wireless Compon. Lett., vol. 14, no. 10, pp. 481-483, Oct. 2004.

[12] V. Carrubba, A. L. Clarke, M. Akmal, J. Lees, J. Benedikt, P. J. Tasker, and S. C. Cripps, "On the extension of the continuous Class-F mode power amplifier," IEEE Trans. Microwave Theory Techn., vol. 59, no. 5, pp. 1294-1303, May 2011.

[13] A. Grebennikov and N. O. Sokal, Switchmode RF Power Amplifiers. New York: Newnes, 2007.

[14] T. Suetsugu and M. K. Kazimierczuk, "Comparison of Class-E amplifier with nonlinear and linear shunt capacitance," IEEE Trans. Circuits Syst. I, vol. 50, no. 8, pp. 1089-1097, Aug. 2003.

[15] S. D. Kee, I. Aoki, A. Hajimiri, and D. Rutledge, "The Class-E/F family of ZVS switching amplifiers," IEEE Trans. Microwave Theory Techn., vol. 51, no. 6, pp. 1677-1690, Jun. 2003.

[16] J. W. Phinney, D. J. Perreault, and J. H. Lang, "Radio-frequency inverters with transmission-line input networks," IEEE Trans. Power Electron., vol. 22, no. 7, pp. 1154-1161, Jul. 2007.

[17] A. Grebennikov, "High-efficiency Class-FE tuned power amplifiers," IEEE Trans. Circuits Syst. I, Reg. Papers, vol. 55, no. 10, pp. 32843292, Nov. 2008.

[18] J. M. Rivas, Y. Han, O. Leitermann, A. D. Sagneri, and D. J. Perreault, "A high-frequency resonant inverter topology with low-voltage stress," IEEE Trans. Power Electron., vol. 23, no. 4, pp. 1759-1771, Jul. 2008.

[19] Z. Kaczmarczyk, "High-efficiency Class $\mathrm{E}, \mathrm{EF}_{2}$, and $\mathrm{E} / \mathrm{F}_{3}$ inverters," IEEE Trans. Ind. Electron., vol. 53, no. 5, pp. 1584-1593, Oct. 2006.

[20] M. Thian and V. F. Fusco, "Analysis and design of Class- $\mathrm{E}_{3} \mathrm{~F}$ and transmission-line Class- $\mathrm{E}_{3} \mathrm{~F}_{2}$ power amplifiers," IEEE Trans. Circuits Syst. I, Reg. Papers, vol. 58, no. 5, pp. 902-912, May 2011.

[21] M. Thian and V. Fusco, "High-efficiency low-voltage-stress Class-EF PA with extended maximum operating frequency," German Microw. Conf., 2011, pp. 1-4.

[22] F. You, S. He, X. Tang, and X. Deng, "High-efficiency single-ended Class-E/ $\mathrm{F}_{2}$ power amplifier with finite $\mathrm{DC}$ feed inductor," IEEE Trans. Microw. Theory Techn., vol. 58, no. 1, pp. 32-40, Jan. 2010.

[23] P. Aflaki, R. Negra, and F. M. Ghannouchi, "Design and implementation of an inverse class-F power amplifier with $79 \%$ efficiency by using a switch-based active device model," IEEE Radio Wireless Symp., 2008, pp. 423-426.

[24] H. Kim, G. Choi, and J. Choi, "A high-efficiency inverse class-F power amplifier using GaN HEMT," Microw. Opt. Technol. Lett., vol. 50, no. 9, pp. 2420-2422, Sep. 2008.

[25] M. Helaoui and F. M. Ghannouchi, "Optimizing losses in distributed multiharmonic matching networks applied to the design of an RF GaN power amplifier with higher than $80 \%$ power-added efficiency," IEEE Trans. Microw. Theory Techn., vol. 57, no. 2, pp. 314-322, Feb. 2009.

[26] P. Singerl, C. Fager, Z. Wang, C. Schuberth, and F. Dielacher, "A highly efficient $1-\mathrm{GHz}, 15-\mathrm{W}$ power amplifier design based on a 50-V LDMOS transistor," IEEE MTT-S Int. Microw. Symp., 2010, pp. 1102-1105.

[27] T. Hwang, et al., "Class-F power amplifier with $80.1 \%$ maximum PAE at $2 \mathrm{GHz}$ for cellular base-station applications," IEEE Wireless and Microw. Tech. Conf., 2013, pp. 1-3.

[28] A. Grebennikov, "High-efficiency Class E/F lumped and transmissionline power amplifiers," IEEE Trans. Microw. Theory Techn., vol. 59, no. 6, pp. 1579-1588, Jun. 2011.

[29] A. Grebennikov, "High-efficiency transmission-line GaN HEMT inverse Class F power amplifier for active antenna arrays," IEEE Asia-Pacific Microw. Conf., 2009, pp. 317-320.

[30] M. M. Ebrahimi, M. Helaoui, and F. M. Ghannouchi, "Efficiency enhancement of a WiMAX switching mode GaN power amplifier through layout optimization of distributed harmonic matching networks," Eur. Microw. Conf., 2009, pp. 379-382.

[31] M. R. Ghajar and S. Boumaiza, "High efficiency GaN Class E amplifier for polar transmitter," Int. Conf. on Signals, Circuits and Syst., 2009, pp. $1-4$. 
This is the author's version of an article that has been published in this journal. Changes were made to this version by the publisher prior to publication.

The final version of record is available at http://dx.doi.org/10.1109/TMTT.2014.2386327

[32] G. F. Collins and J. Wood, "Class-E power amplifier design at $2.5 \mathrm{GHz}$ using a packaged transistor," IEEE Radio Wireless Symp., 2013, pp. 259-261.

[33] K. Chen and D. Peroulis, "A 3.1-GHz Class-F power amplifier with $82 \%$ power-added-efficiency," IEEE Microw. Wireless Compon. Lett., vol. 23, no. 8, pp. 436-438, Aug. 2013.

[34] J. Moon, J. Lee, R. S. Pengelly, R. Baker, and B. Kim, "Highly efficient saturated power amplifier," IEEE Microw. Mag., vol. 13, no. 1, pp. 125131, Jan. 2012.

[35] P. Saad, H. M. Nemati, M. Thorsell, K. Andersson, and C. Fager, "An inverse class-F GaN HEMT power amplifier with $78 \%$ PAE at 3.5 GHz," Eur. Microw. Conf., 2009, pp. 496-499.

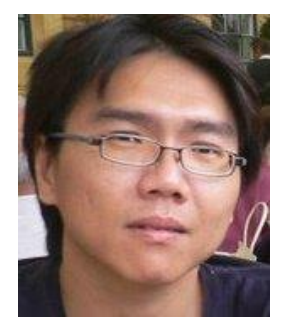

Mury Thian obtained the B.Sc. degree from Atma Jaya Catholic University, Jakarta, Indonesia, the M.Sc. degree from Delft University of Technology, Delft, the Netherlands, and the Ph.D. degree from the Queen's University of Belfast, Belfast, United Kingdom, all in electronics engineering.

He was with Astra International ISUZU (Jakarta, Indonesia), NXP Semiconductors (Nijmegen, the Netherlands), the University of Birmingham (Birmingham, United Kingdom), and Infineon Technologies (Villach, Austria) before joining the Queen's University of Belfast (Belfast, United Kingdom) as a lecturer in 2013.

Dr. Thian has authored over 40 journal and conference papers and has coauthored two book chapters. He has been invited to chair sessions and give talks in a number of IEEE major conferences and workshops. He was a Marie Curie Fellow and the 2008 finalist of the British Association for the Advancement of Science.

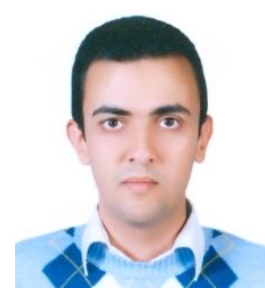

Ayman Barakat (S'14) received the B.Sc. degree in electrical engineering from Ain Shams University, Cairo, Egypt, in 2005, and the M.Sc. degree in electrical engineering from Tampere University of Technology, Tampere, Finland, in 2013. He worked in the telecommunication and electrical industry from March 2006 to July 2013. He is currently an early stage researcher and working toward the $\mathrm{PhD}$ degree in electrical engineering at the Queen's University Belfast, Belfast, United Kingdom. His research interests include switched-mode and Doherty power amplifiers design for multiband transmitters.

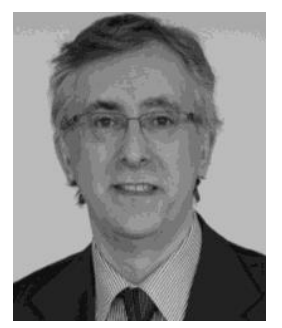

Vincent Fusco (S'82-M'82-SM'96-F'04) obtained his Bachelor's degree in Electrical and Electronic Engineering (First Class Honours) and his Ph.D. in Microwave Electronics from the Queen's University of Belfast. Since 1995, he has held a personal chair in High Frequency Electronic Engineering.

His research interests include nonlinear microwave circuit design, and active and passive antenna techniques. The main focus for this research is in the area of wireless communications. At present he is technical director of the High Frequency Laboratories at ECIT (www.ecit.qub.ac.uk), where he is also director of the International Centre for Research for System on Chip and Advanced Micro-wireless Integration (SoCaM).

Prof. Fusco has published numerous scientific papers in major journals and in referred international conferences, and is the author of two text books. He holds several patents and has contributed invited chapters to books in the field of active antenna design and EM field computation. He is a Fellow of the Royal Academy of Engineering, a Fellow of the Institution of Engineering and Technology (IET), a Fellow of the Institute of Electrical and Electronic Engineers (IEEE), and of the Royal Irish Academy. In 1986, he was awarded a British Telecommunications Fellowship and in 1997 he was awarded the NI Engineering Federation Trophy for outstanding industrially relevant research. 